\title{
Structure of the Quenched Cyanobacterial OCP-Phycobilisome Complex
}

3 Maria Agustina Dominguez-Martin ${ }^{* 1,2,3}$, Paul V. Sauer ${ }^{* 4,5}$, Markus Sutter ${ }^{1,2,3}$, Henning Kirst ${ }^{2,3}$, David Bina $^{6,7}$, Basil J. Greber ${ }^{3,4, \&}$, Eva Nogales ${ }^{3,4,5,8}$, Tomáš Polívka ${ }^{6}$ \& Cheryl A. Kerfeld ${ }^{1,2,3,9(\#)}$

$5 \quad{ }^{1}$ MSU-DOE Plant Research Laboratory, Michigan State University, East Lansing, MI 48824, USA

$6 \quad{ }^{2}$ Environmental Genomics and Systems Biology Divisions, Lawrence Berkeley National Laboratory,

7 Berkeley, CA 94720, USA

$8{ }^{3}$ Molecular Biophysics and Integrated Bioimaging Divisions, Lawrence Berkeley National Laboratory,

9 Berkeley, CA 94720, USA

$10{ }^{4}$ QB3 Institute, Department of Molecular and Cell Biology, University of California, Berkeley, CA, 11 USA.

$12{ }^{5}$ Howard Hughes Medical Institute, University of California, Berkeley, CA, USA.

$13{ }^{6}$ Faculty of Science, University of South Bohemia, Czech Republic.

$14{ }^{7}$ Biology Centre of the Czech Academy of Sciences, Czech Republic.

$15{ }^{8}$ Department of Molecular and Cellular Biology, University of California, Berkeley, CA, USA.

$16{ }^{9}$ Department of Biochemistry and Molecular Biology, Michigan State University, East Lansing, MI

17 48824, USA

$18 \quad{ }^{(*)}$ These authors contributed equally to this work.

$19{ }^{(\&)}$ Present address: Division of Structural Biology, Institute of Cancer Research, London, UK.

$20 \quad{ }^{(\#)}$ Address correspondence to: ckerfeld@1bl.gov

22 The author responsible for distribution of materials integral to the findings presented in this article is:

23 Cheryl A. Kerfeld (ckerfeld@lbl.gov). 


\section{$26 \underline{\text { Abstract }}$}

27 Photoprotection is an essential mechanism in photosynthetic organisms to balance the harvesting of

28 light energy against the risks of photodamage. In cyanobacteria, photoprotective non-photochemical

29 quenching relies on the interaction between a photoreceptor, the Orange Carotenoid Protein (OCP),

30 and the antenna, the phycobilisome (PBS). Here we report the first structure of the OCP-PBS complex

31 at $2.7 \AA$ overall resolution obtained by cryo-electron microscopy. The structure shows that the 6.2

32 MDa PBS is quenched by four $34 \mathrm{kDa}$ OCP organized as two dimers. The complex also reveals that

33 the structure of the active form of the OCP is drastically different than its resting, non-quenching form,

34 with an $\sim 60 \AA$ displacement of its regulatory domain. These results provide a high-resolution blueprint

35 of the structural basis of the protective quenching of excess excitation energy that enables

36 cyanobacteria to harvest light energy and fix $\mathrm{CO}_{2}$ across environmentally diverse and dynamic surface

37 of our planet. 
51 All photosynthetic organisms require photoprotective mechanisms that are activated when their light

52 harvesting antennas absorb excess light-energy. The photoprotective state is elicited not only under

53 high light, but also in the context of drought or temperature stress. In light harvesting complexes the

54 rapid conversion of excess excitation energy into heat before it causes harm is known as non-

55 photochemical quenching (NPQ) ${ }^{1}$. NPQ is also wasteful. In cyanobacteria, organisms ancestral to the

56 chloroplast, $60-80 \%$ of captured light energy is lost to NPQ ${ }^{2}$. In most cyanobacteria, NPQ is triggered

57 by a water-soluble photoreceptor that binds a single carotenoid molecule, the Orange Carotenoid

58 Protein $(\mathrm{OCP})^{3-6}$. Absorption of blue-green light by the resting, orange form of the protein, $\mathrm{OCP}^{\mathrm{O}}$,

59 converts it into the quenching red form, $\mathrm{OCP}^{\mathrm{R}}$ that binds to the phycobilisome (PBS) antenna ${ }^{7-10}$. The

60 structure of the $\mathrm{OCP}^{\mathrm{R}}$ and how it binds to the PBS have evaded elucidation resulting in ongoing debates

61 concerning the mechanism of OCP-induced energy dissipation. Here we report the structure of the

62 OCP-PBS complex from the model organism Synechocystis PCC 6803 at an overall $2.7 \AA$ resolution.

63 We show that the PBS is, in contrast to all previous predictions, quenched by two OCP dimers at two

64 distinct sites of the PBS core. Moreover, our structure reveals an unanticipated drastic domain

65 displacement that takes place when $\mathrm{OCP}^{\mathrm{O}}$ is converted to $\mathrm{OCP}^{\mathrm{R}}$. We also show that quenching occurs

66 via energy transfer and that the 6.2 MDa PBS with its 396 bilin molecules is efficiently quenched by

67 four $34 \mathrm{kDa}$ OCPs. Collectively these data constitute the first structure of a quenched light harvesting

68 antenna and provide a blueprint for the understanding and engineering the photoprotective state of the

69 cyanobacterial PBS.

71 Overview of the structure of the OCP-PBS complex and comparison to the PBS in the light

72 harvesting state.

73 In order to understand the structural basis of OCP-induced NPQ of the cyanobacterial PBS, we have

74 determined the structure of the intact quenched OCP-PBS complex from Synechocystis PCC 6803 at

75 an overall resolution of $2.7 \AA$ by cryo-electron microscopy (cryo-EM), with individual domains 
76 resolved at $2.1 \AA$ (rods) to $2.5-4 \AA$ (core regions and OCP) (Fig. 1 a, Extended Data Fig. 1 and 2,

77 Extended Data Table 1 and Methods). In addition to the PBS (consisting of 320 protein chains and 396

78 bilins) we resolved four OCP chains, each binding a canthaxanthin (CAN) carotenoid (Fig. 1 d)

79 summing to a total molecular weight of 6.3 MDa. For analysis of the Synechocystis PCC 6803 PBS

80 architecture in the light harvesting state we refer to our accompanying study ${ }^{11}$. The quenched state

81 requires a specific PBS configuration, referred to as the up-up conformation in ${ }^{11}$ (Fig. 1 a). In contrast

82 to previous biochemical and spectroscopic studies that suggested that the PBS has one or two OCP

83 binding sites ${ }^{8,12}$, our cryo-EM structure of the OCP-PBS complex reveals that four $\mathrm{OCP}^{\mathrm{R}}$, arranged as

84 two dimers, are bound to the core of the light-harvesting antenna (Top, hereafter T, and Bottom,

85 hereafter B, cylinders) (Fig. 1 a-c) in the fully quenched state.

86 The up-up conformation of PBS in the light harvesting state (no bound $\mathrm{OCP}^{\mathrm{R}}$ ) $^{11}$ and in the quenched

87 (four bound $\mathrm{OCP}^{\mathrm{R}}$ ) state closely superimpose (Extended Data Fig. 3). The binding of the four OCP

88 to the core results in a slight structural perturbation (overall rmsd of $0.44 \AA$ over 12,716 aligned core

$89 \mathrm{C} \alpha$ atoms). Given the multiple conformations of the PBS in its light harvesting state ${ }^{11}$ each

90 distinguished by different position of the top rod (denoted therefore as the mobile rod, see Extended

91 Data Fig. 3), it is notable that the binding site of OCP is situated right below the attachment of the

92 mobile rod to the core. Therefore, when the mobile rod is in the down position ${ }^{11}$, it completely occludes

93 the OCP binding site. We do not observe any partially quenched states (e.g. consisting of only one

94 OCP-dimer bound to the PBS), possibly because our sample contained a large excess of OCP to PBS

95 (20:1) to favor the formation of the fully quenched complex (Extended Data Fig. 4 c, d). Our model

96 suggests that while the mobile rod of the unoccupied side of a partially quenched PBS complexes could

97 move freely between its up and down states the fully quenched state requires the up-up PBS

98 conformation in order to have all four $\mathrm{OCP}^{\mathrm{R}}$ binding sites accessible. Recently, the in situ higher order

99 organization of the PBS was described ${ }^{13}$; it is made up of closely appressed PBS in the up-up state. 
bioRxiv preprint doi: https://doi org/10.1101/2021.11.15.468719; this version posted November 15,2021 . The copyright holder for this preprint (which was not certified by peer review) is the author/funder, who has granted bioRxiv a license to display the preprint in perpetuity. It is made available under aCC-BY-NC-ND 4.0 International license.

OCP-Phycobilisome Paper

100 Even in this compact arrangement, the OCP binding dimer sites are accessible, suggestive of the 101 potential for these light harvesting arrays to be rapidly quenched by the OCP (Extended Data Fig. 5).

a

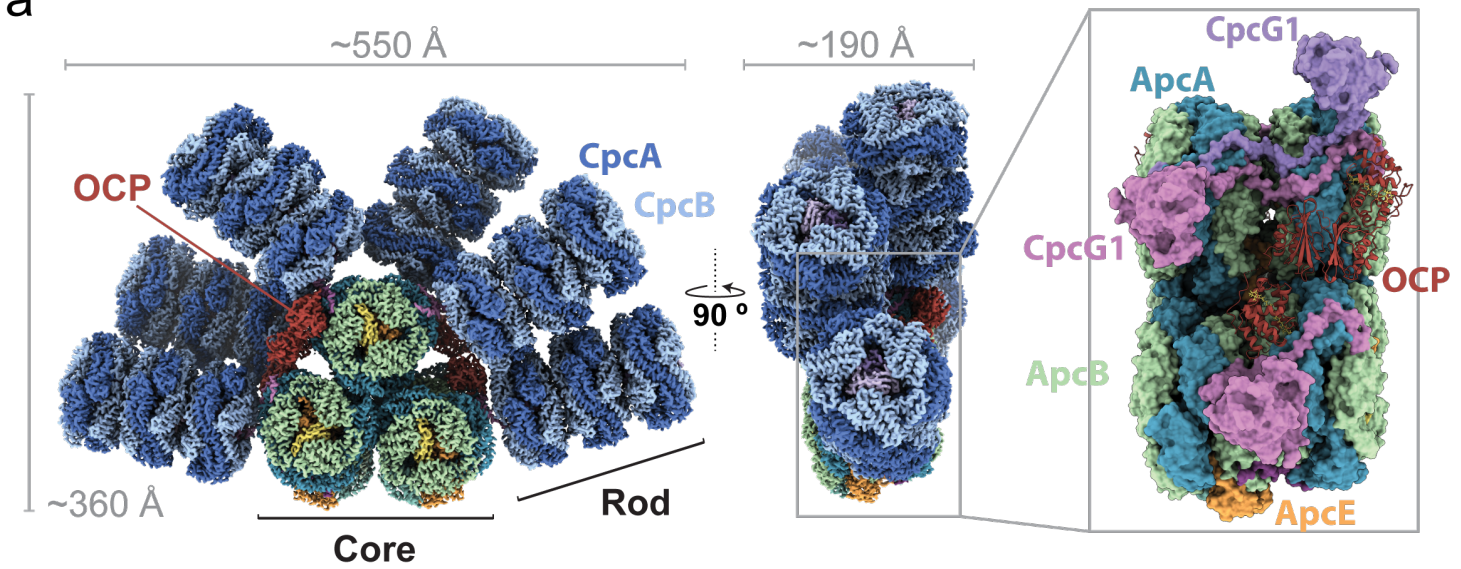

b
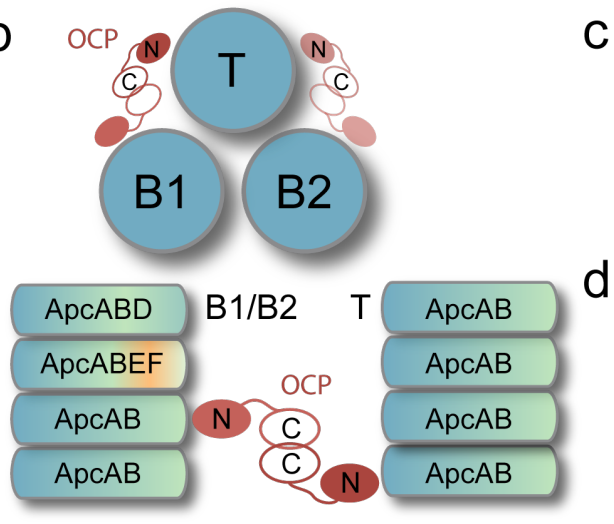

C

d
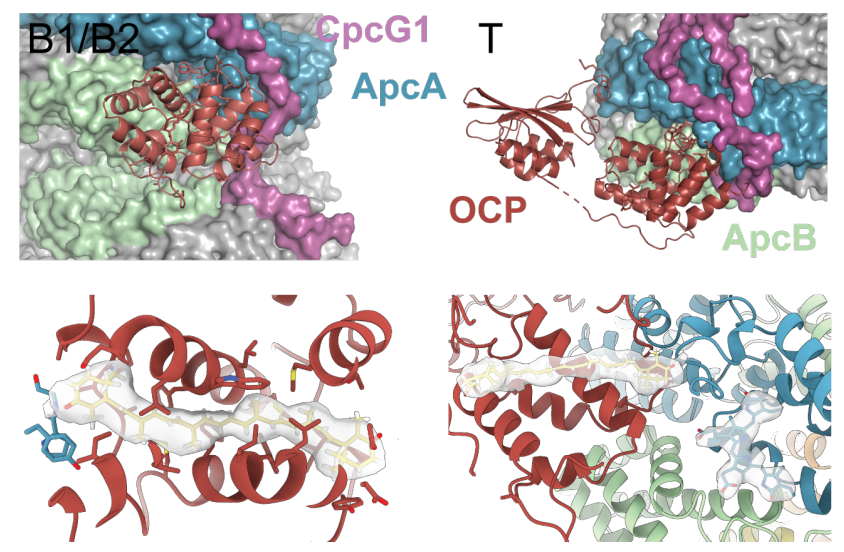

Figure 1: Overview of the $O C P^{\mathrm{R}}$-PBS structure. a, Composite cryo-EM map of the complete $\mathrm{OCP}^{\mathrm{R}}$-PBS complex, front

and side view. Individual maps and the consensus map can be found in the Extended Data Fig. 1. Inset showing a side-

view in surface representation, omitting the rods. $\mathbf{b}$, Schematic of the $\mathrm{OCP}^{\mathrm{R}}-\mathrm{PBS}$ core complex. $\mathbf{c}$, Overview of the OCP

bound to the PBS in B1/B2 cylinder (Bottom cylinders) and T cylinder (Top cylinder). The PBS proteins that interact with

OCP colored. d, Close-up views showing the density for the carotenoid and the atomic models for the carotenoid and its closest bilin.

\section{The Structure of the $\mathrm{OCP}^{\mathrm{R}}$}

111 Our OCP-PBS structure also reveals the structure of $\mathrm{OCP}^{\mathrm{R}}$, the red active form of OCP (Fig. 2).

112 Structurally, the inactive $\mathrm{OCP}^{\mathrm{O}}$ is composed of two domains, an N-terminal domain (NTD) with an $\alpha$ -

113 helical fold unique to cyanobacteria and a mixed $\alpha / \beta$ C-terminal domain (CTD) joined by a flexible

114 linker, a single carotenoid molecule that spans both domains ${ }^{6}$ (Fig. 2 a). However, the OCP $^{\mathrm{R}}$ bound to 
115 the PBS shows that the NTD and CTD are completely separated and only connected by an extension

116 of the interdomain linker (Fig. 2 a, b). In addition to the elongated structure and the complete

117 translocation of the carotenoid into the NTD consistent with previous findings ${ }^{9,14}$, our structure shows

118 that in $\mathrm{OCP}^{\mathrm{R}}$ the $\mathrm{CTD}$ has rotated $\sim 220^{\circ}$ around the NTD, resulting in a net translation of about $60 \AA$

119 for the center of mass of the CTD (Fig. 2 b, Supplementary video 1). This translation is slightly

120 different for the $\mathrm{T}$ vs $\mathrm{B}$ cylinder bound state $(61 \AA$ for $\mathrm{T}, 63 \AA$ for $\mathrm{B})$. The translocation of the

121 carotenoid from a position shared between the N- and C-terminal domains completely into the NTD

122 along with the detachment of the CTD exposes the $\beta 1$ surface, which is buried between both domains

123 in $\mathrm{OCP}^{\mathrm{O}}$, and thus allows it to interact with the binding site on the PBS (Fig. 2 a).

124 We previously determined the X-ray crystal structure of the isolated NTD of OCP (PDB 4XB4) ${ }^{9}$,

125 known as the Red Carotenoid Protein (RCP), that also can quench the PBS ${ }^{9}$. While the NTD of the

$126 \mathrm{OCP}^{\mathrm{R}}$ and the isolated RCP superpose with an rmsd of $0.4 \AA$ over 121 aligned $\mathrm{C} \alpha$ atoms and exhibit a

127 similar carotenoid conformation, the protein environment surrounding the chromophore differs due to

128 the presence of the NTD-CTD linker (residues G166-T194) in $\mathrm{OCP}^{\mathrm{R}}$. Residues E174-V177 are ordered

129 across the $\beta 2$ surface (Fig. 2 a) and are within $4 \AA$ of the carotenoid. Moreover, the positioning of

130 linker residue E174 possibly contributes to the pronounced asymmetry of the electrostatic distribution

131 around the carotenoid. The net charge is negative around the $\beta 2$ ring and positive around the $\beta 1$ ring,

132 which is proximal to a bilin (Extended Data Fig. 6), likely stabilizing the $O C P^{\mathrm{R}}$ in its binding site and

133 fixing the mutual position of the carotenoid in OCP and the closest bilin in the PBS.

134 Unexpectedly, two OCPR, one bound to the B-cylinder, the other bound to the T-cylinder form a dimer 135 interacting via their CTD domains (Fig. 2 c). The density for the CTD dimers is weak, indicating that 136 they are mobile. The dimerization is in contrast quite stable, with a buried surface area of $\sim 1,150 \AA^{2}$.

137 The residues making up the dimerization interface are conserved in OCP (Fig. $2 \mathrm{~d}$ and Extended Data 138 Fig. 7 a, c) and are shielded from solvent in the $\mathrm{OCP}^{\mathrm{O}}$ by interaction with the N-terminal extension 139 (NTE, residues 1-18). Accordingly, the $\mathrm{OCP}^{\mathrm{R}}$ structure connects two apparently disparate observations 
140 concerning structural changes associated with photoactivation: that $\mathrm{OCP}^{\mathrm{R}}$ is a dimer in solution ${ }^{15}$, and

141 that dimerization is mediated by residues exposed by dissociation of the N-Terminal extension during

142 photoactivation $^{10,14}$.

143 Reactivation of the quenched PBS depends on the $14 \mathrm{kDa}$ fluorescence recovery protein (FRP), which 144 interacts with the OCP-CTD ${ }^{16,17}$. Given the $\mathrm{OCP}^{\mathrm{R}}$ dimers we observe in the quenching complex, we 145 propose that an FRP dimer binds to the CTD-dimer. Each CTD could then form a complex with an 146 FRP monomer while disrupting the CTD dimer, with FRP serving to protect the newly exposed 147 hydrophobic residues on the CTD from solvent. The detached CTDs are then able to approach the 148 NTD again to allow for re-association and formation of $\mathrm{OCP}^{\mathrm{O}}$. This proposed mechanism is consistent 149 with (i) previous data from controlled proteolysis experiments that showed that the CTD is not essential 150 for quenching and was proposed to play a regulatory role ${ }^{10}$ and (ii) recent biochemical data suggesting 151 that in catalyzing the reversion from $\mathrm{OCP}^{\mathrm{R}}$ to $\mathrm{OCP}^{\mathrm{O}}$, the $\mathrm{OCP}^{\mathrm{R}}$ and $\mathrm{FRP}$ binding occurs in a 2:2 ratio ${ }^{18}$. 152 One of the main differences of the conformation of the $\mathrm{CTD}$ in $\mathrm{OCP}^{\mathrm{R}}$ is the loop formed by residues 153 P276-W277-F278 which covers the entrance to the tunnel in the CTD that is occupied by carotenoid 154 in $\mathrm{OCP}^{\mathrm{O}}$ (Extended Data Fig. 7 b). Based on an X-ray footprinting model ${ }^{19}$, the bound FRP could 155 potentially also facilitate re-opening of the carotenoid tunnel for carotenoid re-entry by binding and 156 repositioning those residues. 

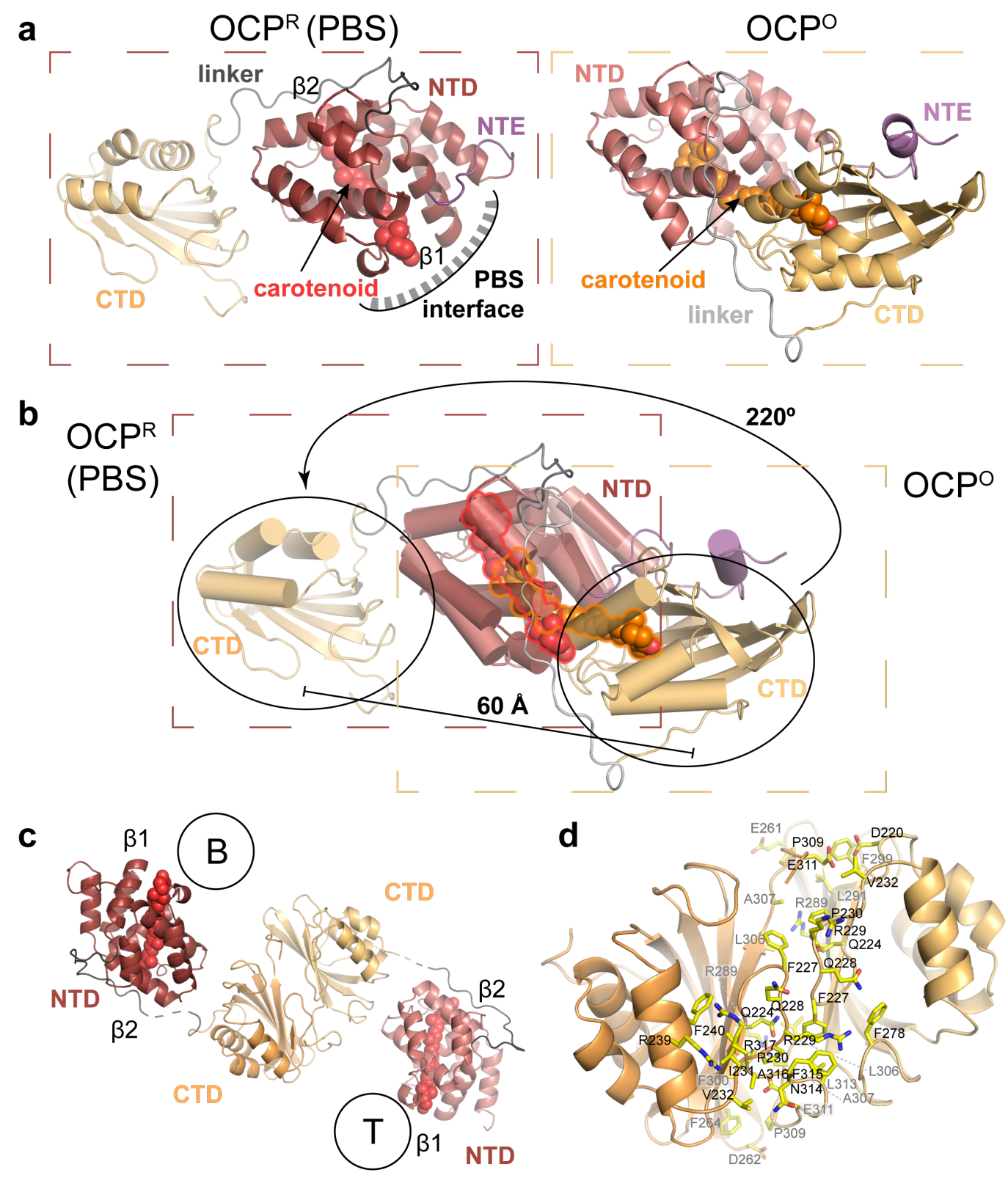

158 Figure 2: Structural changes associated with the photoconversion from $\mathbf{O C P}^{\mathbf{O}}$ to $\mathbf{O C P}^{\mathrm{R}} \mathbf{a}, \mathrm{Structure}$ of $\mathrm{OCP} P^{\mathrm{R}}($ left $)$ in 159 comparison to $\mathrm{OCP}^{\mathrm{O}}$ (right, $\left.\mathrm{PDB}: 4 \mathrm{XB} 5\right)^{9} . \beta 1$ and $\beta 2$ denote terminal rings of the carotenoid. b, Superimposed ribbon 160 structures of $\mathrm{OCP}^{\mathrm{R}}$ and $\mathrm{OCP}^{\mathrm{O}}$ in cartoon representation with helices as cylinders. CAN is shown as outlined spheres and 161 colored in red for the $\mathrm{OCP}^{\mathrm{R}}$ and orange for $\mathrm{OCP}^{\mathrm{O}}$. The displacement of the $\mathrm{CTD}$ is indicated with an arrow. c, Structure of 162 the $\mathrm{OCP}^{\mathrm{R}}$ dimer via interaction of the CTDs. Circles with B and T represents bottom and top PBS cylinder, respectively. 163 d, Close-up view of the CTD-CTD interface. Residues involved in the interaction within $4 \AA$ are shown as yellow sticks. $164 \mathrm{NTD}=\mathrm{N}$-terminal domain, $\mathrm{CTD}=\mathrm{C}$-terminal domain, $\mathrm{NTE}=\mathrm{N}$-terminal extension. 


\section{The PBS-OCP interaction}

166 Contrary to all previous predictions for the structure of the quenching complex, four $\mathrm{OCP}^{\mathrm{R}}$ bind to the

167 PBS core. The binding sites are located at the top and the bottom cylinders of the PBS (Fig. $1 \mathrm{a}, \mathrm{b}$ ).

168 Several, some mutually exclusive, models based on a wide range of experimental techniques have been

169 proposed for the OCP-PBS interaction ${ }^{20-26}$. Some of the suggested gross characteristics of the interface, such as binding of the OCP to Allophycocyanin-A/B (ApcA/B, APC660) ${ }^{22-24}$ are confirmed and now

171 precisely detailed by our structure (Fig. 1). $\mathrm{OCP}^{\mathrm{R}}$ interacts mostly with the outermost ApcA/B disc in

172 the $\mathrm{T}$ cylinder (Fig. $1 \mathrm{~b}, \mathrm{c}$ ). The two top binding sites (here named Ta and $\mathrm{Tb}$ ) are identical other than

173 minor differences in sidechain conformations. On the $\mathrm{B}$ cylinders, $\mathrm{OCP}^{\mathrm{R}}$ is bound to the two ApcA/B

174 discs with only a minor interaction with an ApcB from the ApcABEF disc (Fig. 1 b, c). Furthermore,

175 our structure shows that $\mathrm{OCP}^{\mathrm{R}}$ interacts with the $\mathrm{CpcG1}$ rod-linker, a conserved subunit assumed to

176 be present in the ancestor of the Cyanobacteria ${ }^{27}$, contributing to the surface of interaction (Fig. $1 \mathrm{c}, 3$

177 b Extended Data Table 2 and 3).

178 The interaction surfaces between the $\mathrm{OCP}^{\mathrm{R}}$ and the $\mathrm{B}$ cylinders $\left(\sim 1400 \AA^{2}\right)$ are identical and are 179 slightly larger than the buried surface of interaction with the T cylinder $\left(\sim 1200 \AA^{2}\right)$. The larger 180 interaction surface of the B cylinder binding site results from additional interactions with the N181 terminal extension (G10, I11, F12 and N14) and with the interdomain linker residues A165 and G166 182 with the ApcB (G21 and D25) from the ApcABEF disc (Fig. 3 a, b and Extended Data Table 2). A 183 subset of the N-terminal extension residues released from the CTD upon conversion to OCP ${ }^{\mathrm{R}}$ (Fig. 2a) 184 interact with the B cylinder. Particularly, the conserved residue F12 shows extensive interactions with 185 residues from the ApcA (highly conserved E76 and T80), ApcB (highly conserved Y62), and with 186 P215 and M216 from the rod-core linker CpcG1 (Extended Data Table 2). The release of the N187 terminal extension from the CTD in the conversion from $\mathrm{OCP}^{\mathrm{O}}$ to $\mathrm{OCP}^{\mathrm{R}}$ not only enables the CTD188 CTD dimerization, but also provides additional contact points to the PBS. 
189 The majority of $\mathrm{OCP}^{\mathrm{R}}$ residues involved in the interaction with the PBS are mainly from the $\beta 1$ face

190 of the NTD (Fig. 3 a, Extended Data Tables 2, 3). Residues from the CTD (N314, F315 and R317) are

191 also in proximity to the PBS core but their density is very weak and therefore it is unlikely that those

192 are specific interactions. The close vicinity does however explain why several studies using 193 crosslinkers identified residues in the linker or in the CTD as interacting with $\mathrm{PBS}^{20,21}$. The conserved

194 R155 from the NTD is in the center of the interaction surface next to the carotenoid and interacts with

195 the highly conserved ApcA residue Y73 (Fig. 3 c). Additional interactions occur between R155 and

196 E76 (conserved ApcA) at the B cylinder and G74, E76 and M77 (conserved ApcA residues) at the T

197 cylinder (Extended Data Tables 2,3). While most of the central interactions of OCP with PBS involve

198 ApcA, there are also significant peripheral interactions with ApcB such as E54 that interacts with 199 several residues from OCP (Fig. 3 e).

200 A further completely unexpected and large portion $\left(\sim 300 \AA^{2}\right)$ of the $\mathrm{OCP}^{\mathrm{R}}$ interface with the PBS is 201 formed by the loop that connects the two discontinuous four-helix bundles that constitute the NTD. 202 These residues, T52-A58, are predominantly small side chains that are strongly conserved (Fig. 3 d). 203 The backbone of the OCP in this region closely approaches the ApcA backbone (G69) and between 204 OCP residues (A55 and A58) with distances of only 5-6 $\AA$ explaining the conservation of 205 small sidechains. Furthermore, the $\beta 1$ ring of the CAN is surrounded by four highly conserved residues 206 (P68, G69, G70 and Y73) from the ApcA (Fig. $3 \mathrm{c}$ and Extended Data Tables 2, 3), stabilizing the 207 center-to-center distance between both chromophores at $\sim 27 \AA ̊$ (Fig. 4 a, b). 
a
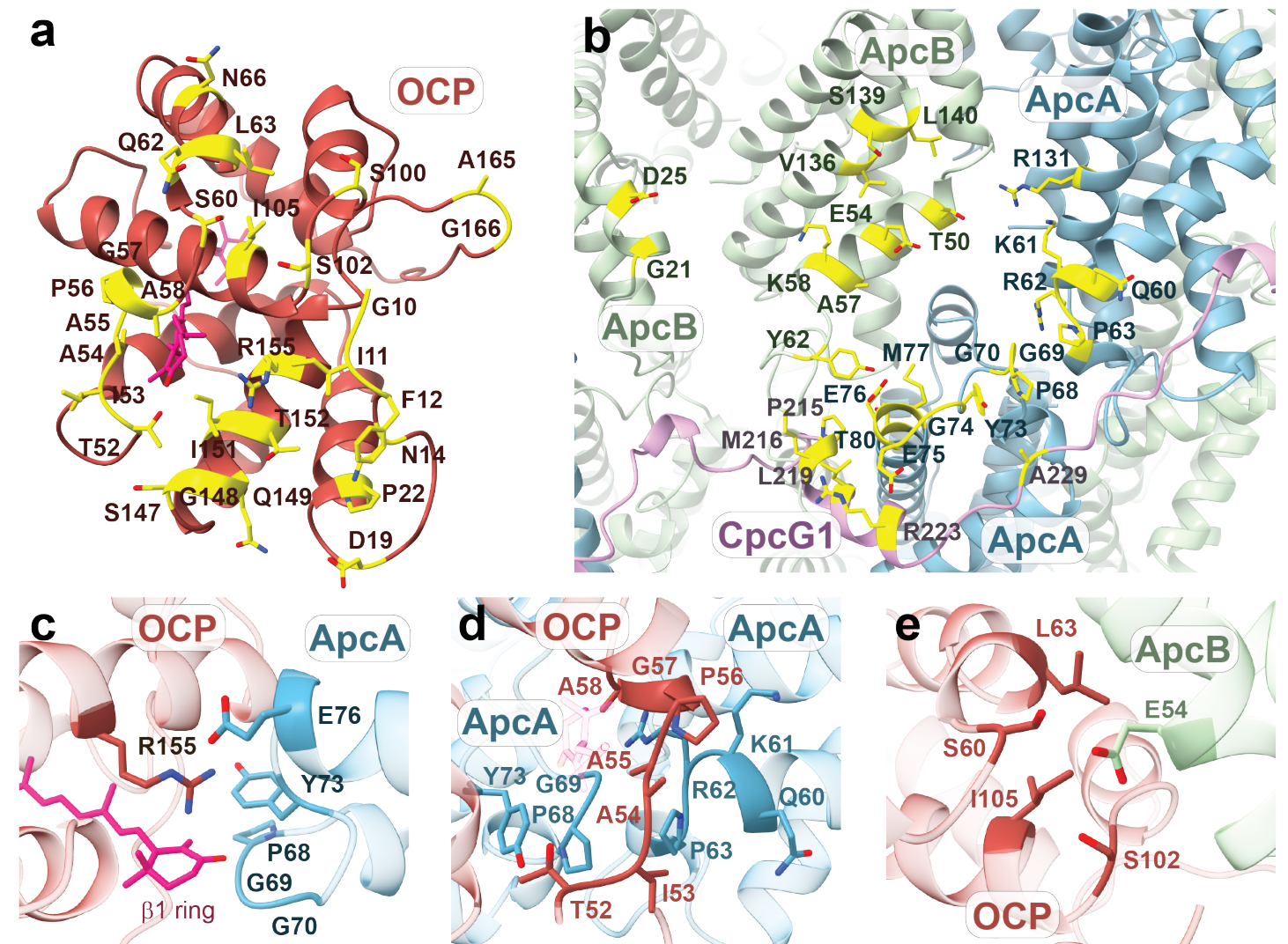

2
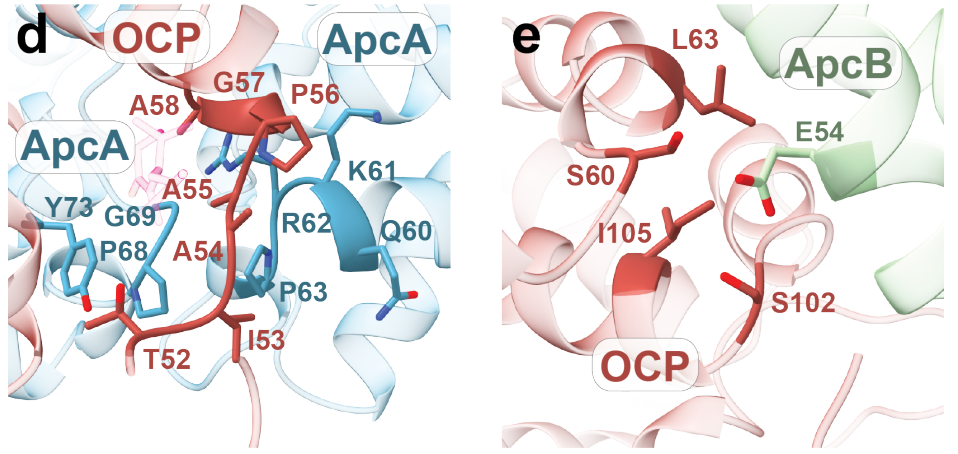

Figure 3: PBS-OCP interactions. a and b, Interface residues of OCP (a) and ApcAB and CpcG1 (b) within $4 \AA$ of

each other in the major interface shown in bottom cylinder. c, Close-up view of the interaction between the OCP

211 surface surrounding the $\beta 1$ ring of the carotenoid and ApcA (B cylinder). d, Close-up view of the interaction between

212 the OCP loop (T52-A58) and ApcA (B cylinder). e, Interaction between E54 from ApcB and the OCP residues.

\section{Mechanism of the OCP-induced PBS quenching}

215 We used the OCP-PBS structure to model the PBS quenching by the carotenoid bound to OCP ${ }^{\mathrm{R}}$. We

216 assume that only energy transfer is involved in the quenching mechanism ${ }^{28}$. Other potential

217 mechanisms, such as excitonic quenching or electron transfer ${ }^{26}$, are unlikely given the $\sim 27 \AA$ distance

218 between the CAN in $\mathrm{OCP}^{\mathrm{R}}$ and the closest bilin (Fig. $4 \mathrm{a}, \mathrm{b}$ ). The simulation was carried out for the

219 whole OCP-PBS complex, and the unquenched state of PBS was simulated by setting the transition

220 dipole moment of CAN in OCP to zero, effectively switching off the OCP quenching (details of the

221 model are provided in the Methods section). 
222 The results of modeling the energy flow through the OCP-PBS complex in quenched and unquenched

223 states are shown in Fig. 4 c. After excitation of a PBS rod, the population is transferred to the APC

224 core within the first $100 \mathrm{ps}$ and this process is not affected by OCP. The lifetime of the APC core is

225 significantly shortened in the quenched state, proving that structural arrangement of OCP allows for

226 efficient quenching of the core via energy transfer mechanism. The results show that for each of the

227 four OCP CAN molecules there is one bilin characterized by bilin-to-carotenoid transfer time constant

228 of $29 \pm 3$ ps and one bilin transferring at $89 \pm 3$ ps (for a CAN dipole moment of $2.3 \mathrm{D}$, see Extended

229 Data Fig. 5 a, b). No other pairwise time constants shorter than 200 ps were found. These individual

230 bilin-to-CAN quenching rates are much longer than the sub-ps value proposed by Tian et al. ${ }^{29}$.

231 However, the values obtained from our model based on the presented OCP-PBS structure are clearly

232 short enough to ensure efficient quenching that agrees with experimental data, but only under

233 conditions where four OCPs are bound to PBS. If we leave only one, two or three OCPs active, the

234 quenching efficiency decreases significantly (Fig. 4 d, Extended Data Fig. 5 c, d). Thus, the key

235 structural feature ensuring efficient quenching via energy transfer mechanism is the binding of two

236 dimers of the $\mathrm{OCP}^{\mathrm{R}}$ to the PBS. Moreover, our modeling suggests that OCP bound to one PBS within

237 an array can quench energy captured by a different array PBS due lateral energy transfer, making the

238 array arrangement efficient at low light and at same time rapidly responsive when exposed to higher

239 light intensities (Extended Data Fig. 5 e, f). 

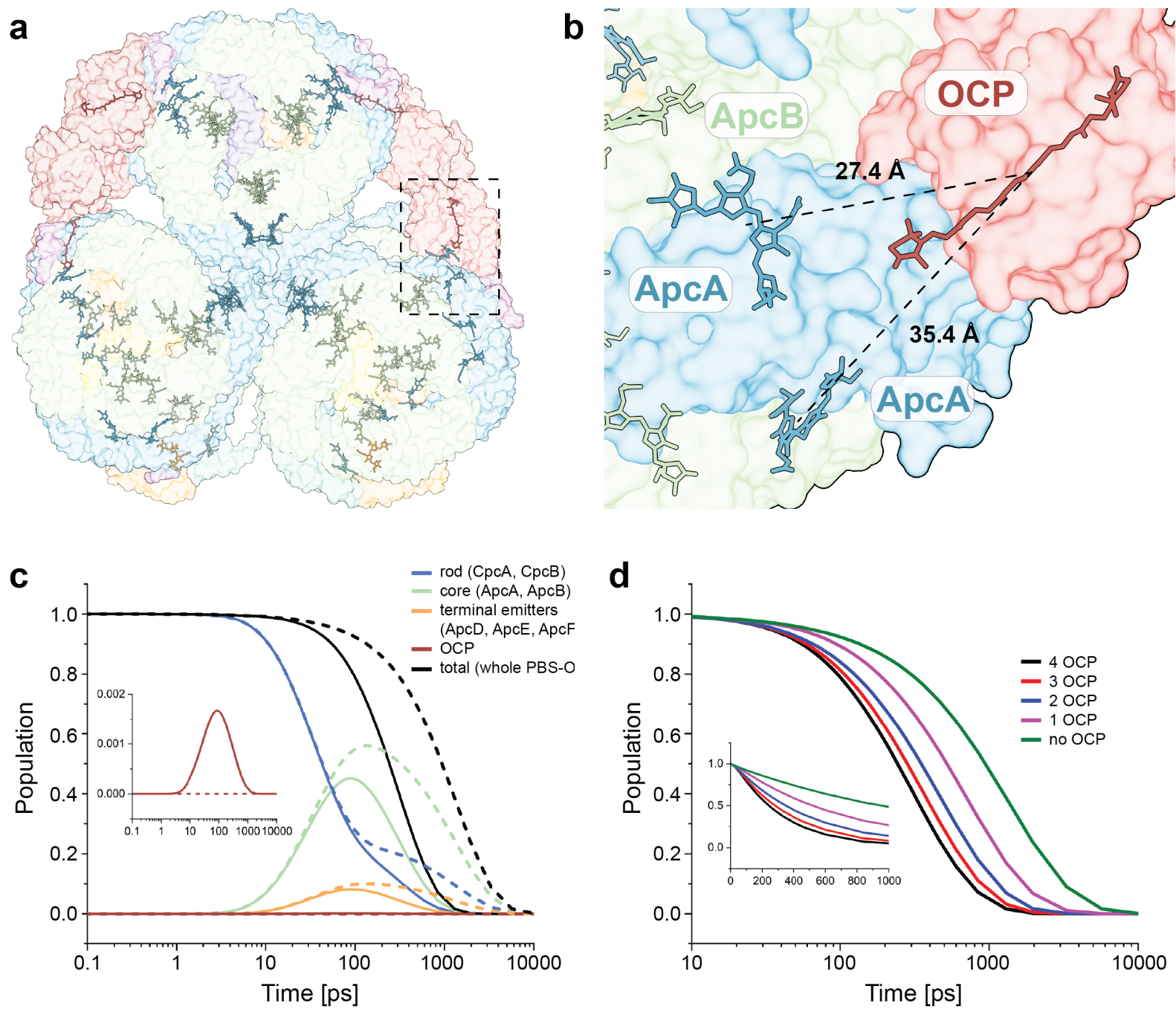

242 Figure 4. OCP-induced PBS quenching mechanism. a, Overview of the bilins and carotenoid (CAN). Dashed lines

243 outline the region shown in panel b. b, Close-up view of the two closest carotenoid-bilin pairs with indicated distance. c,

244 Simulated excitation energy flow in quenched (solid) and unquenched (dashed) OCP-PBS. The initial population is placed

245 at the end of rod. The curves monitor the evolution of an excited state population of pigments located in rod, core, and

246 terminal emitters. The black traces show the total population of the whole OCP-PBS complex. Inset shows the time profile of population of excited CAN in OCP, which is negligible due to the short (3.5 ps) CAN lifetime that is significantly shorter than the time constant of bilin-to-CAN energy transfer. d, Effect of the number of active OCPs on the total excitation lifetime in PBS. Inset shows the first nanosecond in linear time scale. Identical excitation conditions were used in all five simulation runs. 
254 The efficient quenching is important for fitness of the organism in its natural environment, but the 255 overall NPQ process is counterproductive in cyanobacterial mass cultures, decreasing the 256 photosynthetic sunlight-to-biomass conversion efficiency by up to $60 \%{ }^{2,30}$. Indeed, tuning the balance 257 between light harvesting and photoprotection is arguably the greatest challenge in realizing the full 258 potential of cyanobacteria as solar powered cellular factories ${ }^{31}$. The structure of the quenched state of 259 a cyanobacterial PBS provides the requisite description of excitation energy transfer in the quenching 260 process to inform efforts to modify the PBS, OCP and/or FRP to alleviate this energetic wasteful 261 process $^{30,32}$ while at the same time providing the first high resolution model of a quenched light 262 harvesting antenna with implications for understanding and engineering both natural and articial 263 photosynthetic systems. 
Methods

\section{Preparation of the Synechocystis PCC 6803 Phycobilisome}

281 Synechocystis PCC 6803 were grown photoautotrophically in a BG11 medium. Cells were kept in a 282 rotary shaker $(100 \mathrm{rpm})$ at $30^{\circ} \mathrm{C}$, under $3 \% \mathrm{CO}_{2}$ enrichment, illuminated by white fluorescent lamps 283 with a total intensity of about $30 \mu \mathrm{mol}$ photons $\mathrm{m}^{-2} \mathrm{~s}^{-1}$. The protocol used for PBS isolation was based 284 on ${ }^{33,34}$ and the procedure as described in ${ }^{11}$.

\section{Expression and purification of Synechocystis PCC 6803 OCP-CAN holoprotein in E. coli}

286 A C-terminal 10x His-tagged Synechocystis PCC 6803 ocp gene (slr1963) was cloned in a pCDFDuet 287 (Novagen), resulting in a plasmid named pEP4. Then, BL21(DE3) cells were transformed 288 simultaneously with pEP4 and pAC-CANTHipi plasmid (Addgene plasmid \#53301) and induced with $289100 \mu \mathrm{M}$ of Isopropyl ß-d-1-thiogalactopyranoside (IPTG) and incubate overnight at $25^{\circ} \mathrm{C}$. OCP-CAN 290 was firstly purified by a Ni-NTA affinity chromatography (His Trap affinity column, GE Healthcare), 291 yielding a mixture of apo-and holo-OCP protein. Then, to separate the holoprotein from the apoprotein, 292 a hydrophobic interaction chromatography using a linear decreasing $\left(\mathrm{NH}_{4}\right)_{2} \mathrm{SO}_{4}$ gradient (from $1.5 \mathrm{M}$ 293 to 0 M) (HiTrap HIC phenyl column, GE Healthcare) was applied to the mixture. The maximum 294 extinction coefficient of CAN $\left(118,000 \mathrm{M}^{-1} \mathrm{~cm}^{-1} ; 1: 1\right.$ binding stoichiometry of CAN:OCP) was used 295 to determine the concentration of the OCP-CAN holoprotein. The absorption spectrum of the E. coli296 expressed 6803 OCP inactive and photoconverted to the red form is consistent with previous literature 297 report $^{9}$ (Extended Data Fig. 4).

\section{$298 \quad$ Protein separation}

299 The isolated PBS samples were treated as described in ${ }^{11}$. The purity of isolated OCP protein was 300 assessed by Coomassie Brilliant Blue stained SDS-PAGE (Extended Data Fig. 4).

\section{Absorption and fluorescence spectrum measurement}

302 OCP-CAN holoproteins were buffer-exchanged into $50 \mathrm{mM}$ Tris- $\mathrm{HCl}, \mathrm{pH} 8.0$, and $200 \mathrm{mM} \mathrm{NaCl}$ 303 before spectroscopic measurements. PBS and OCP-CAN absorption spectra were collected with a Cary 
30460 spectrophotometer (Agilent). Photoconversion of the inactive $\mathrm{OCP}^{\mathrm{O}}$ samples to the active $\mathrm{OCP}^{\mathrm{R}}$ 305 form was carried out with $15 \min$ of blue LED illumination $(\lambda \max =470 \mathrm{~nm}$, Philips Lumileds LXML306 PB01-0030) at 1,000 $\mu \mathrm{mol}$ photons $\mathrm{m}^{-2} \mathrm{~s}^{-1}$. The fluorescence emission spectra of the PBS were 307 recorded at room temperature from 600 to $800 \mathrm{~nm}$ in a fluorimeter (TECAN Spark 20M multimode 308 microplate reader) with an excitation wavelength of $580 \mathrm{~nm}$.

\section{In vitro OCP-PBS biotinylated complex formation}

311 The PBS sample was biotinylated as described in ${ }^{11}$. The OCP was previously illuminated for 10 312 minutes by blue-LED light $\left(\lambda \max =470 \mathrm{~nm}, 1,000 \mu \mathrm{mol}\right.$ photons $\left.\mathrm{m}^{-2} \mathrm{~s}^{-1}\right)$ to activate it. Then, for OCP313 PBS complex formation, activated OCP was added to the isolated biotinylated PBS (in $0.75 \mathrm{M}$ 314 potassium phosphate $\mathrm{pH} 7.5$ ), giving an OCP to PBS ratio of 20. The samples were illuminated again 315 under the same light for 20 minutes at room temperature. Fluorescence spectra were measured to 316 quantify the OCP-induced quenching (Extended Data Fig. 4).

\section{Cryo-EM sample preparation of OCP-PBS}

318 Cryo-EM sample preparation was carried out as described in $^{11}$. For sample preparation, we used 319 Quantifoil Au 300 mesh 2/1 grids covered with a home-made streptavidin monolayer, which were 320 manufactured as described previously ${ }^{35}$. To apply the sample, grids were first rehydrated in buffer A 321 (375 mM potassium phosphate, $\mathrm{pH}$ 7.5) and then blotted dry with filter paper. To promote the 322 conversion of $\mathrm{OCP}^{\mathrm{O}}$ to $\mathrm{OCP}^{\mathrm{R}}$ the $\mathrm{OCP}-\mathrm{PBS}$ sample was illuminated with blue light at a wavelength of $323470 \mathrm{~nm}$ for $5 \mathrm{~min}$ on the bench prior to application to the grid. $4 \mu$ l of $\mathrm{OCP}^{\mathrm{R}}$-PBS at a concentration 324 of $5.3 \mathrm{mg} / \mathrm{ml}(0.86 \mu \mathrm{M})$ in buffer $\mathrm{B}(750 \mathrm{mM}$ potassium phosphate, $\mathrm{pH} 7.5)$ were added to the grid 325 and then incubated on the bench for 60 seconds. Grids were washed on two $10 \mu 1$ drops of buffer C $326(375 \mathrm{mM}$ potassium phosphate, $\mathrm{pH} 7.5,3 \% \mathrm{w} / \mathrm{v}$ trehalose, $0.01 \% \mathrm{v} / \mathrm{v} \mathrm{NP} 40,0.05 \% \mathrm{w} / \mathrm{v}$ beta327 octylglucoside) before being carefully wicked with Whatman filter paper. $1 \mu 1$ of buffer $\mathrm{C}$ was added 328 immediately, and the grid lifted into a FEI Mark IV Vitrobot. The grid was then manually blotted for 
$3292-3 \mathrm{~s}$ at $18^{\circ} \mathrm{C}$ and $100 \%$ humidity before plunging into a liquid ethane-propane $(3: 1) \mathrm{mix}^{36}$. During the 330 process the OCP-PBS was exposed to ambient light for a total of approximately 2-3 minutes between 331 pipetting and vitrification, in addition to the initial illumination.

\section{Cryo-EM data collection OCP-PBS}

334 The data collection pipeline used in this study was the same as for the PBS without OCP ${ }^{11} .13427$ 335 movies were collected on a Titan Krios G3i microscope operating at a voltage of $300 \mathrm{kV}$, equipped 336 with a Gatan K3 direct electron detector operating in CDS mode ${ }^{37}$ and a GIF Quantum energy filter 337 with a $20-\mathrm{eV}$ slit width. Movies were acquired with SerialEM $^{38}$ in super-resolution counting mode 338 with a super-resolution pixel size of $0.525 \AA$ using an image shift collection scheme with active beam 339 tilt correction, a defocus range from $-0.5 \mu \mathrm{m}$ to $-1.6 \mu \mathrm{m}$ and a total exposure of $50 \mathrm{e}^{-} / \AA^{2}$.

\section{Image processing $\mathbf{O C} \mathbf{P}^{\mathrm{R}}$-PBS}

342 The image processing pipeline was similar to PBS without $\mathrm{OCP}^{11}$. All super-resolution movies were 343 aligned, gain corrected and binned by 2 using MotionCorr2 as implemented in RELION3 ${ }^{39}$. The 344 background streptavidin lattice in the motion corrected micrographs was subtracted using in-house 345 scripts $^{35}$. These subtracted micrographs were then imported into CryoSPARC ${ }^{40}$ for patch CTF 346 estimation and further image processing.

347 Particles were picked from a subset of 870 micrographs using templates generated from the PBS ${ }^{\text {up-up }}$ 348 reconstructions from dataset 1 of the PBS without $\mathrm{OCP}^{11}$ and with a box size of 1000 pixels. 349 Heterogeneous refinement yielded a single good class that reached 3.4 Å resolution during refinement. 350 Subsequently, particles were picked from all micrographs using the same templates and a box size of 351720 pixels. From a total of $\sim 2,500,000$ particles $\sim 1,100,000$ particles classified into a single good class 352 which corresponded to PBS-OCP ${ }^{\mathrm{R}}$, with no other conformations in the dataset apparent. Inspection of 353 the reconstruction revealed flexibility in the core region, resulting in elongated density artifacts in 
354 certain parts of the map and smeary density for OCP. To speed up subsequent processing steps the

355 boxsize was cropped to 360 pixels in real space, thus excluding the peripheral rods. 3D variability 356 analysis (3DVA) revealed an overall twisting motion of the core and the partial loss of the bottom 357 ApcAB hexamer rings on either side, presumably because of the overall fragility of the complex. A 358 subset of particles showing improved OCP density was identified using 3DVA in cluster mode. This 359 subset $(\sim 341,000$ particles $)$ was subjected to non-uniform refinement to yield a final resolution of 2.6 $360 \AA$.

361 This particle stack was used to further improve several features of the core. To further improve the 362 density for OCP, particle subtraction followed by local refinement was performed to obtain a map of 363 OCP bound to the top ApcAB double hexamer at 2.6 ̊ resolution with the map quality for OCP visibly 364 improved. To improve the C-terminal domain of OCP, this latter map was analyzed by 3DVA and a 365 particle subset with better density for CTD, but a slightly worse overall resolution was identified $366(\sim 180,000$ particles, $2.8 \AA \AA$ resolution $)$.

367 Similar strategies were used to obtain locally refined maps of the entire top cylinder $(2.6 \AA)$ and the 368 entire B2 cylinder (2.5 $)$, each with improved map quality at the same nominal resolution. To obtain 369 a reconstruction of the holo $\mathrm{OCP}^{\mathrm{R}}$-PBS including the rods the cropped particles were re-extracted with 370 a box size of 720 pixels and subjected to homogenous refinement, yielding an overall resolution of 2.7 $371 \AA$.

372 To obtain a high-resolution reconstruction of the rods, templates obtained from dataset 1 from the PBS 373 sample without OCP were used to pick and extract particles with a box size of 360 pixels. After 2D 374 classification a set of $\sim 2,100,000$ particles was selected for further processing. CTF refinement and 375 non-homogenous refinement yielded a reconstruction with a resolution of $2.1 \AA$, thus reaching Nyquist 376 limit. Further classification of the particle set to probe the possible presence of different rod protomers 377 within one PBS complex always yielded the same conformation. 
378 All processing was carried out using C1 symmetry and resolutions were estimated with the FSC 0.143

379 criterion. For interpretability and illustrations, reconstructions were sharpened using DeepEMhancer

$380 \quad{ }^{41}$ with the default tight mask preset.

\section{Atomic model building and refinement PBS-OCP ${ }^{\mathrm{R}}$}

382 Atomic models were built by first fitting existing structures of the $\alpha$ and $\beta$-PC subunits into the density 383 for orientation (4F0T and homology models based on algal homologs from $5 \mathrm{Y} 6 \mathrm{P} / 6 \mathrm{KGX}$ ) that were 384 then fit into the density using COOT 0.95 (ref. $^{42}$ ). Linker domains were built ab initio by tracing the 385 backbone and assigning the sequence and fitting the sidechains using COOT 0.95 (ref. ${ }^{42}$ ). Models 386 were built sequentially, starting with the maps of the locally refined B- and T-cylinders and the locally 387 refined T-disc 2 . The resulting atomic models were refined using the map of the core with appropriate 388 restraints with the real space refinement program in PHENIX 1.19.2 (ref. ${ }^{43}$ ). The rods were modelled 389 and refined independently using the same approach. To arrive at a model for the entire PBS-OCP 390 complex, maps and models for the individual rods were rigid-body docked into the density of the holo391 PBS-OCP ${ }^{\mathrm{R}}$ complex, which resulted in an unambiguous orientation of each rod. Because the holo392 PBS-OCP ${ }^{\mathrm{R}}$ maps are not resolved enough in the distal rod regions to allow for model refinement, 393 models of the full complex are for visualization only.

\section{$394 \quad$ Model of PBS Quenching}

395 The model used to calculate energy transfer in OCP-PBS complex is the same as described in our 396 accompanying study ${ }^{11}$. Here, the key modification is the inclusion of the CAN bound to OCP. For the 397 transition dipole moment of the $\mathrm{S}_{0}-\mathrm{S}_{1}$ transition of CAN (because the $\mathrm{S}_{1}$ state should be the energy 398 acceptor), we used the value of $2.3 \mathrm{D}$ obtained from calculations using combination of molecular 399 modelling and quantum chemistry ${ }^{44}$. We note that this is a mean value obtained for CAN in $\mathrm{OCP}^{\mathrm{O}}$. 400 Thus, the actual value for $\mathrm{OCP}^{\mathrm{R}}$ bound to PBS may differ, but we note that binding to OCP increased 401 the mean dipole from $1.7 \mathrm{D}$ in THF solution to $2.3 \mathrm{D}$ in $\mathrm{OCP}^{44}$. The significant asymmetry in charge 
402 distribution around CAN when OCP is bound to PBS (Extended Data Fig. 6) is comparable to that in

$403 \mathrm{OCP}^{\mathrm{O}}, 45$ justifying our approximation. The effect of the actual value of the carotenoid transition dipole

404 moment were also studied, as shown in Extended Data Fig. 5 a, b. As expected, larger $\mathrm{S}_{1}$ dipole 405 moment increases the efficiency of excitation quenching. To calculate the spectral overlap, the 406 hypothetical absorption spectrum of the acceptor, which is associated with the forbidden $\mathrm{S}_{0}-\mathrm{S}_{1}$ 407 transition of CAN, was modelled as a mirror image of the $\mathrm{S}_{1}$ emission spectrum of the carotenoid 408 peridinin reported earlier ${ }^{46}$. The resulting spectrum was then shifted to match the expected 0-0 energy 409 of carotenoid in $\mathrm{OCP}^{47}$. The CAN $\mathrm{S}_{1}$ lifetime of 3.5 ps was used in simulation, based on the value 410 reported in Kuznetsova et al. $^{45}$. However, since the $\mathrm{S}_{1}$ lifetime of CAN is much shorter than the bilin411 to-carotenoid quenching time, the actual value of the $S_{1}$ lifetime has little effect on quenching 412 dynamics. To evaluate the validity of the quenching model, we compared simulated decay-associated 413 spectra (see ${ }^{11}$ for details) with those obtained from fitting the experimental data ${ }^{29}$. The results are 414 shown in Extended Data Fig. 5 c, d, demonstrating reasonable match between our model based on 415 energy transfer quenching and experimental data obtained from time-resolved fluorescence.

\section{Bioinformatics}

418 We obtained HMM profiles for each phycobiliprotein by collecting all phycobilisome sequences using 419 jackhmmer (https://www.ebi.ac.uk/Tools/hmmer/search/jackhmmer) against the rp75 Uniprot 420 proteome with a starting sequence of each Synechocystis PCC 6803 phycobilisome protein. Apc and 421 linker proteins were then each aligned using ClustalW $\mathrm{W}^{48}$ and used to generate a phylogenetic tree using 422 RAxML $^{49}$ with default parameters and PROTGAMMAW substitution matrix. Sequences from major 423 branches that contain each Synechocystis PCC 6803 protein were aligned with ClustalW and trimmed 424 with trim $\mathrm{Al}^{50}$ and the trimmed alignment was used to generate HMM profiles for each protein. The 425 HMM profiles were then combined into a phycobilisome sequence HMM library. We then downloaded 426 the 500 most complete non-redundant cyanobacterial proteomes from Uniprot and searched them with 
the combined HMM profile library and occurrences of each type of phycobilisome protein were

428 counted. We then compared the protein counts with those of Synechocystis PCC 6803 and chose the

42950 closest proteomes for sequence conservation analysis. For each phycobilisome protein we then

430 aligned those sequences with $\mathrm{ClustalW}^{48}$, manually checked the alignment, trimmed them with $431 \operatorname{trim} \mathrm{Al}^{50}$ and visualized the protein sequence conservation with Weblogo $3.74^{51}$.

\section{$\underline{\text { Structural visualization and accession codes }}$}

436 System, version 1.7 Schrödinger, LLC). Protein interfaces were analyzed using PISA ${ }^{54}$ and Profunc $^{55}$ 437 at the European Bioinformatics Institute. The pymol APBS plugin ${ }^{56}$ was used with default parameters 438 to calculate the electrostatics surfaces shown in Extended Data Fig. 6.

439 The atomic coordinates have been deposited in the Protein Data Bank with the accession codes 7SC9, $4407 \mathrm{SCB}, 7 \mathrm{SCC}, 7 \mathrm{SCA}$.

441 The EM maps have been deposited in the Electron Microscopy Data Bank with the accession codes 442 EMDB-25030, EMDB-25031, EMDB-25032, EMDB-25033 and EMDB-25068.

443 All other data are available from the corresponding authors upon reasonable request.

\section{Acknowledgements}

445 CAK and MADM dedicate this manuscript to the late Dr. Nicole Tandeau de Marsac. Molecular 446 graphics images were produced using the UCSF Chimera package from the Resource for 447 Biocomputing, Visualization, and Informatics at the University of California, San Francisco 448 (supported by NIH P41 RR-01081). DB and TP thanks the Czech Science Foundation, grant No. 19449 28323X. DB also acknowledges institutional support RVO:60077344. Research in the Kerfeld lab was 450 supported by the Office of Science of the U.S. Department of Energy DE-FG02-91ER20021. This 451 project has received funding from the European Union's Horizon 2020 research and innovation 
452 programme under the Marie Sklodowska-Curie grant agreement No. 795070. EN is a Howard Hughes

453 Medical Institute Investigator.

\section{Author contributions}

455 MADM and PVS designed and performed experiments, interpreted results. CAK designed and 456 supervised the project. HK helped with the sample preparation, interpreted results. MS refined the 457 structures and interpreted results. DB and TP performed the model for the quenching. BJG performed 458 initial characterization of the specimen for cryo-EM. MADM, PVS and CAK wrote the manuscript 459 with help from all authors.

\section{Competing interest}

461 The authors declare no competing interests. 
bioRxiv preprint doi: https://doi.org/10.1101/2021.11.15.468719; this version posted November 15, 2021. The copyright holder for this preprint (which was not certified by peer review) is the author/funder, who has granted bioRxiv a license to display the preprint in perpetuity. It is made available under aCC-BY-NC-ND 4.0 International license.

OCP-Phycobilisome Paper

EXTENDED DATA

a

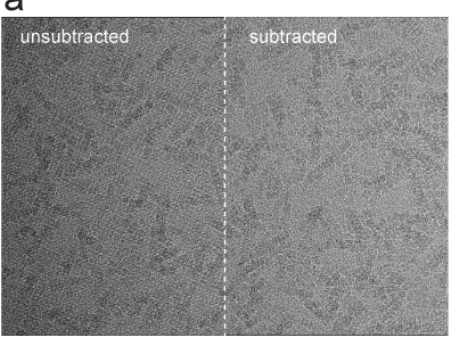

C

Motion correction, lattice subtraction, CTF estimation template based picking: PBS

145,280 particles from 870 micrographs, $1000 \mathrm{px}$

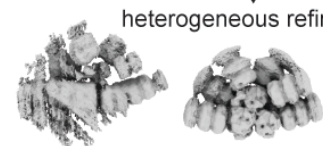

$45 \%$

Homogeneous refinement

67,099 particles, $3.4 \AA$

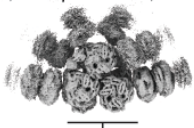

template based picking

$2,542,658$ particles from 13,427 micrographs, $720 \mathrm{px}$ heterogeneous refinement

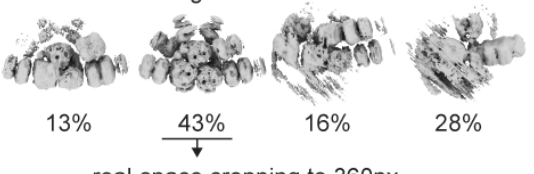

real-space cropping to $360 \mathrm{px}$

CTF \& NU-refinement, 1,082,835 particles, $2.6 \AA$

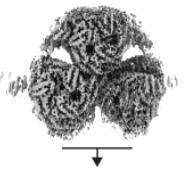

3DVA, 3 modes, 4 clusters
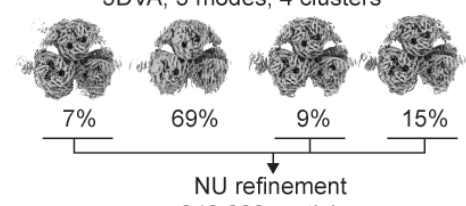

340,839 particles

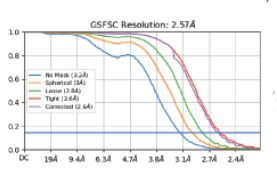

Extended Data Fig. 1: Cryo-EM analysis of the OCP-PBS complex. a, Example raw micrograph before and after
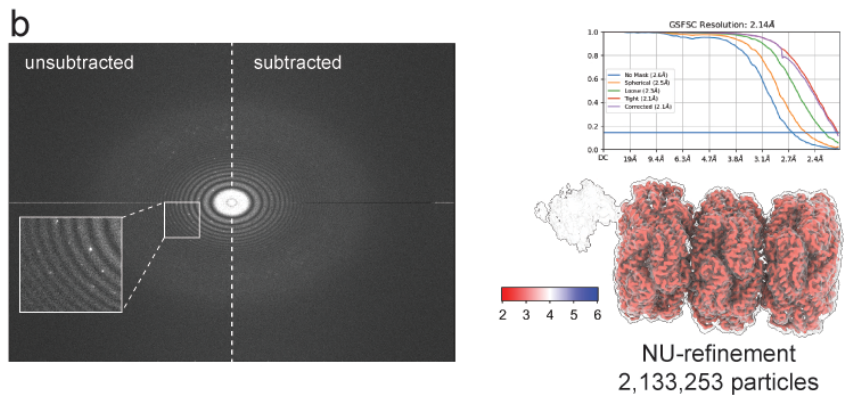

5,198,356 particles from 13,427 micrographs, 360px
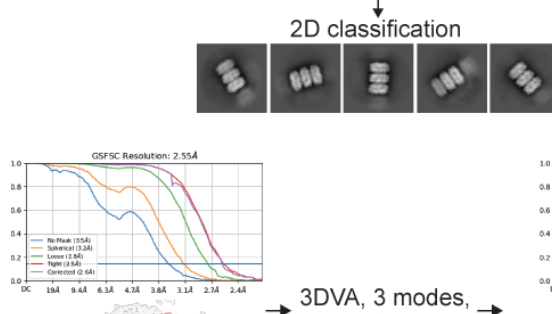

2 clusters

T-cylinder disc 2

176,804 particles

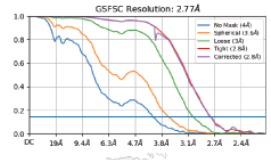

T-cylinder disc 1
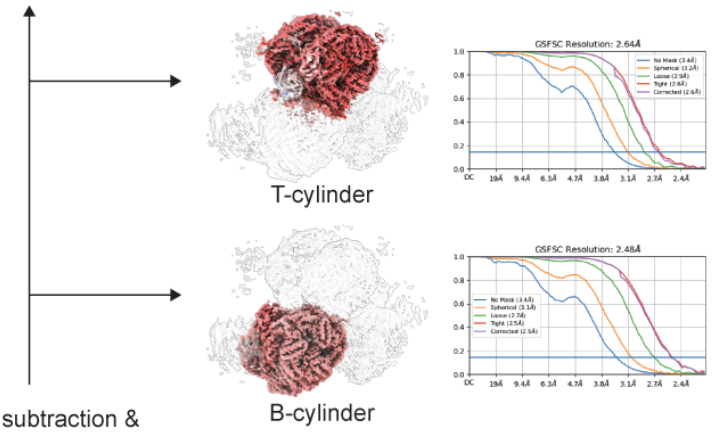

particle subtraction \&

un-cropping to $720 p x$ \&

338,725 particles

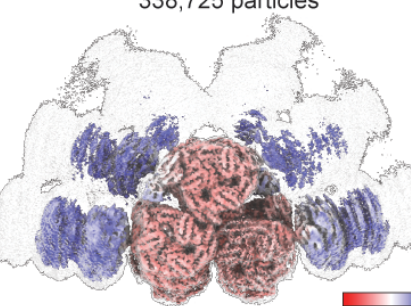

PBS-OCPR $\quad 23456$

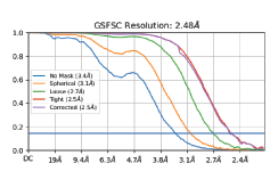

homogeneous refinement

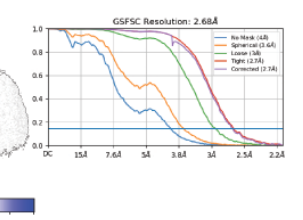

streptavidin lattice subtraction. b, Fourier transform of (a) showing Bragg diffraction from the streptavidin crystal before subtraction. c, The workflow for the cryo-EM data processing. Red to blue color shading represents local resolution estimates at $\mathrm{FSC}=0.5$ ranging from 2 to $6 \AA$. Maps of PBS-OCP and the rod are shown with two different thresholds to show flexible regions and connectivity. 
bioRxiv preprint doi: https://doi.org/10.1101/2021.11.15.468719; this version posted November 15,2021 . The copyright holder for this preprint (which was not certified by peer review) is the author/funder, who has granted bioRxiv a license to display the preprint in perpetuity. It is made available under aCC-BY-NC-ND 4.0 International license.

OCP-Phycobilisome Paper

a
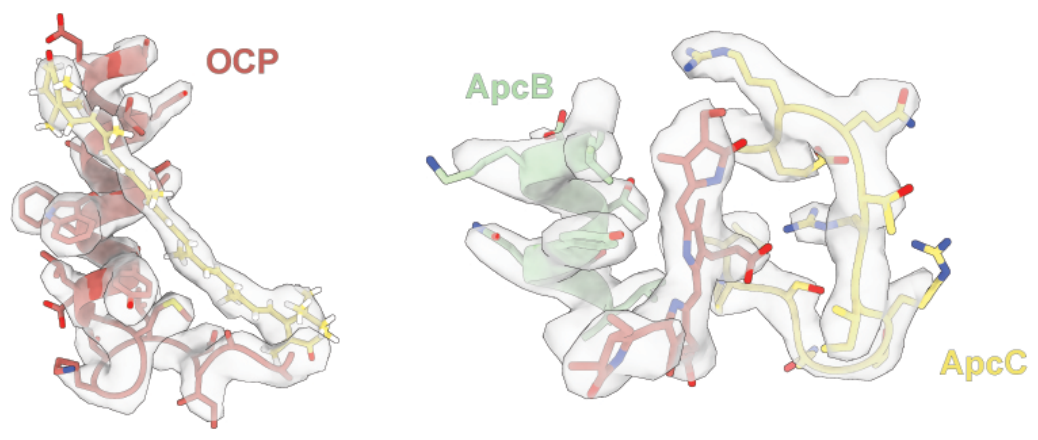

b
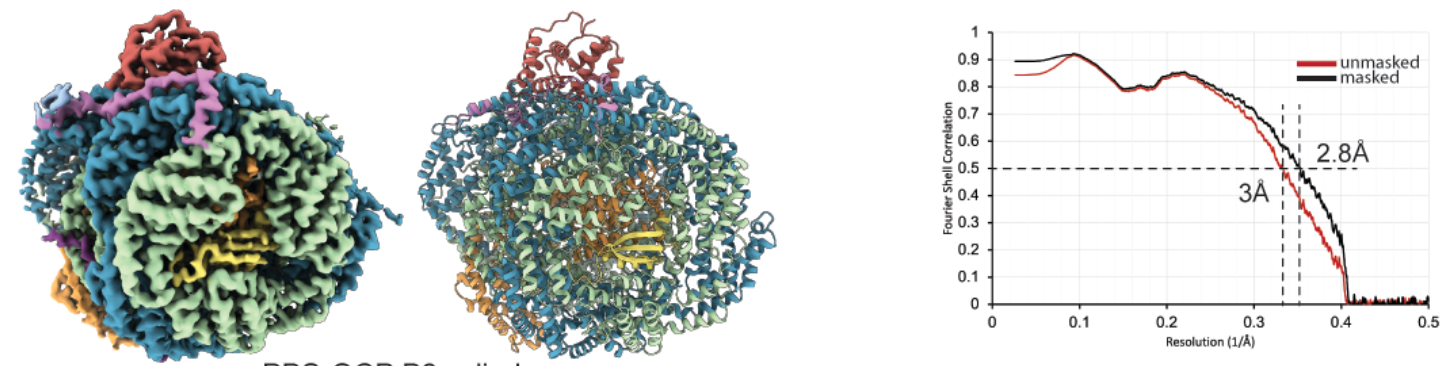

C
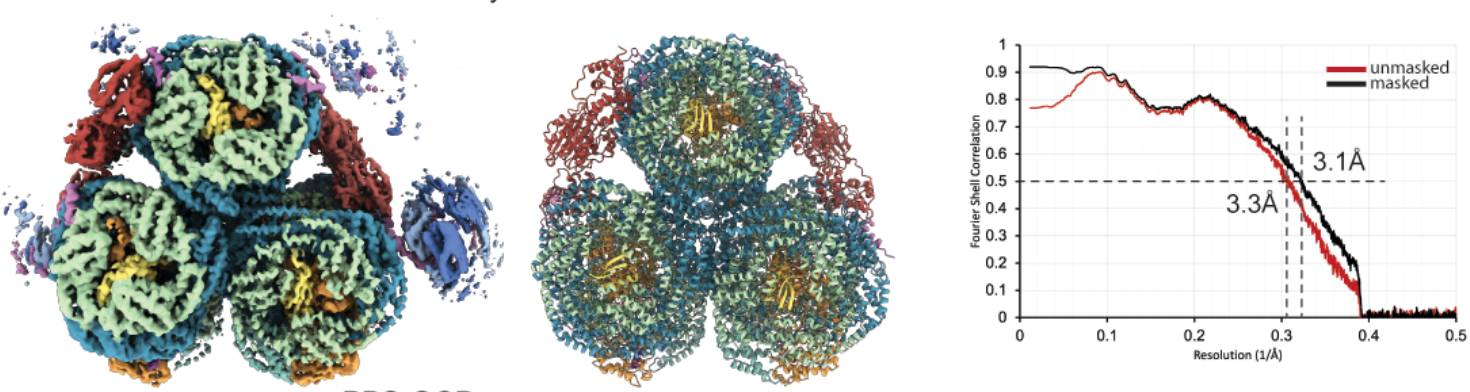

d

PBS-OCP core
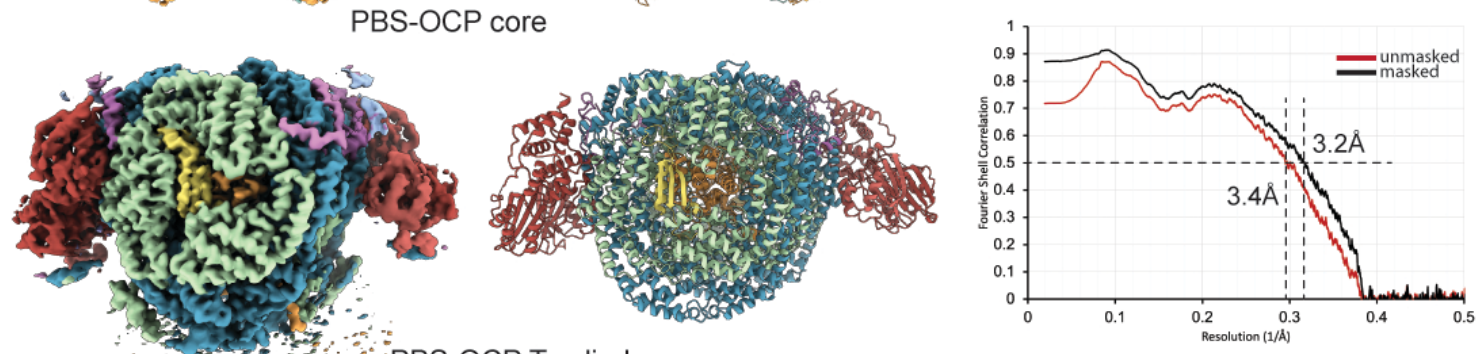

e
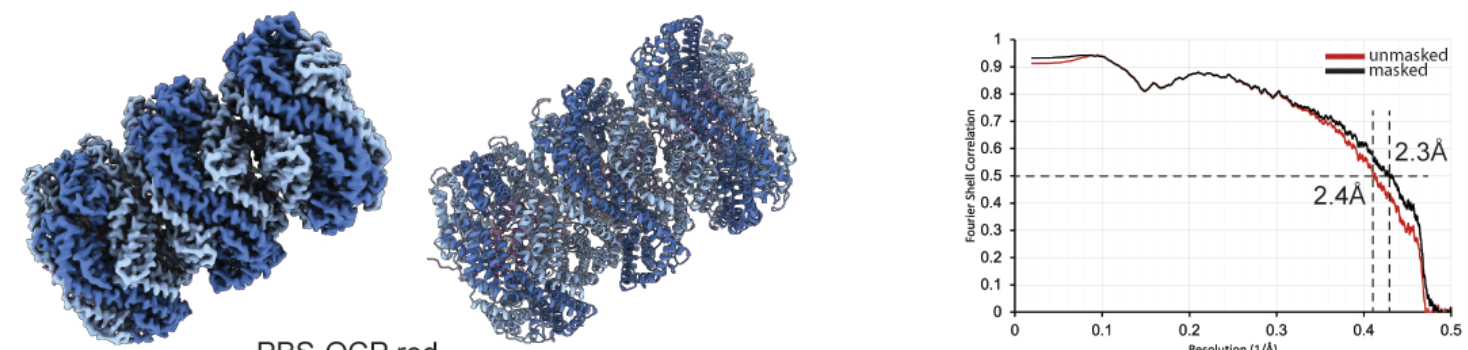

486 Extended Data Fig. 2: Map and Model quality of PBS-OCP $\mathbf{P}^{\mathbf{R}}$. a, examples of map density quality from different regions of the PBS-OCP ${ }^{\mathrm{R}}$. b-e, Map, model and corresponding Fourier shell correlation (FSC) curves. Resolution of masked and unmasked models are indicated at $\mathrm{FSC}=0.5$. 
bioRxiv preprint doi: https://doi org/10.1101/2021 11.15.468719; this version posted November 15,2021 . The copyright holder for this preprint (which was not certified by peer review) is the author/funder, who has granted bioRxiv a license to display the preprint in perpetuity. It is made available under aCC-BY-NC-ND 4.0 International license.

OCP-Phycobilisome Paper

a

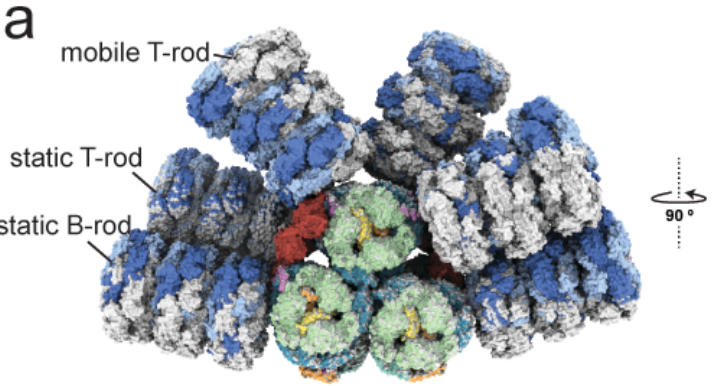

b

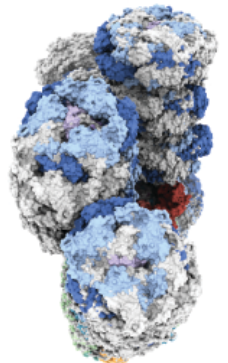

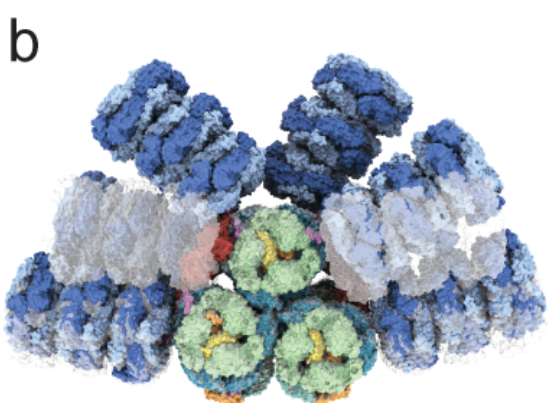

491 Extended Data Fig. 3. Structural comparison between light-harvesting PBS and quenched PBS. a, Superimposition

492 of the PBS-OCP ${ }^{\mathrm{R}}$ (colored as in Fig. 1) and PBS up-up (grey). b, Superimposition of the PBS-OCP ${ }^{\mathrm{R}}$ and the PBS down-

493 down conformation (transparent surface). Both shown in surface representation.

a
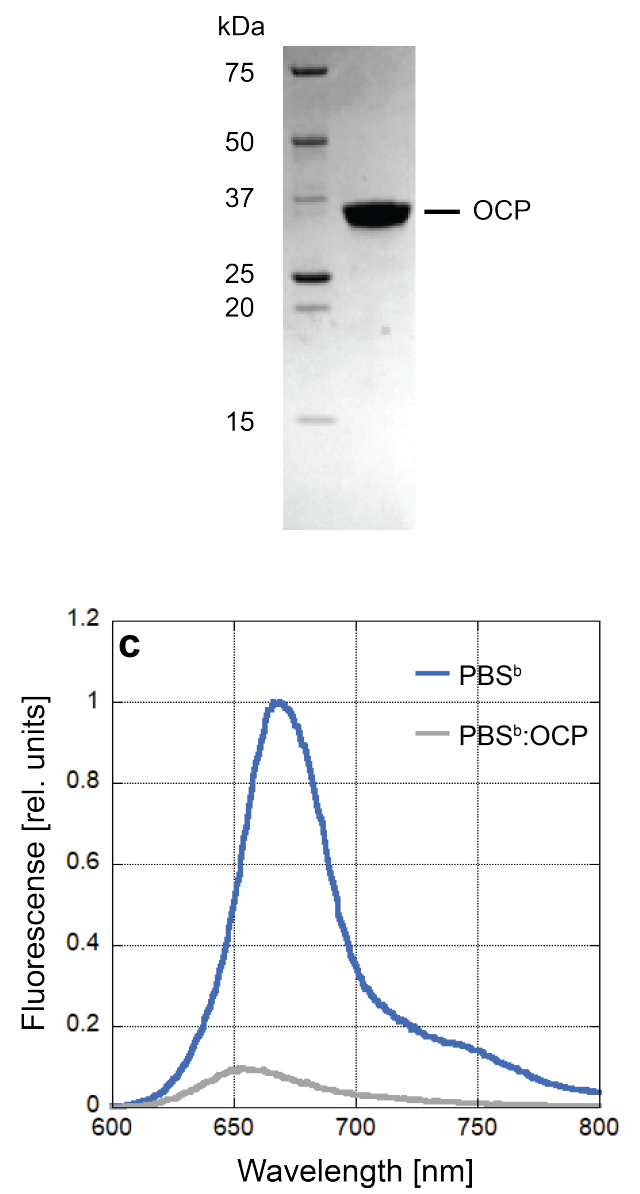
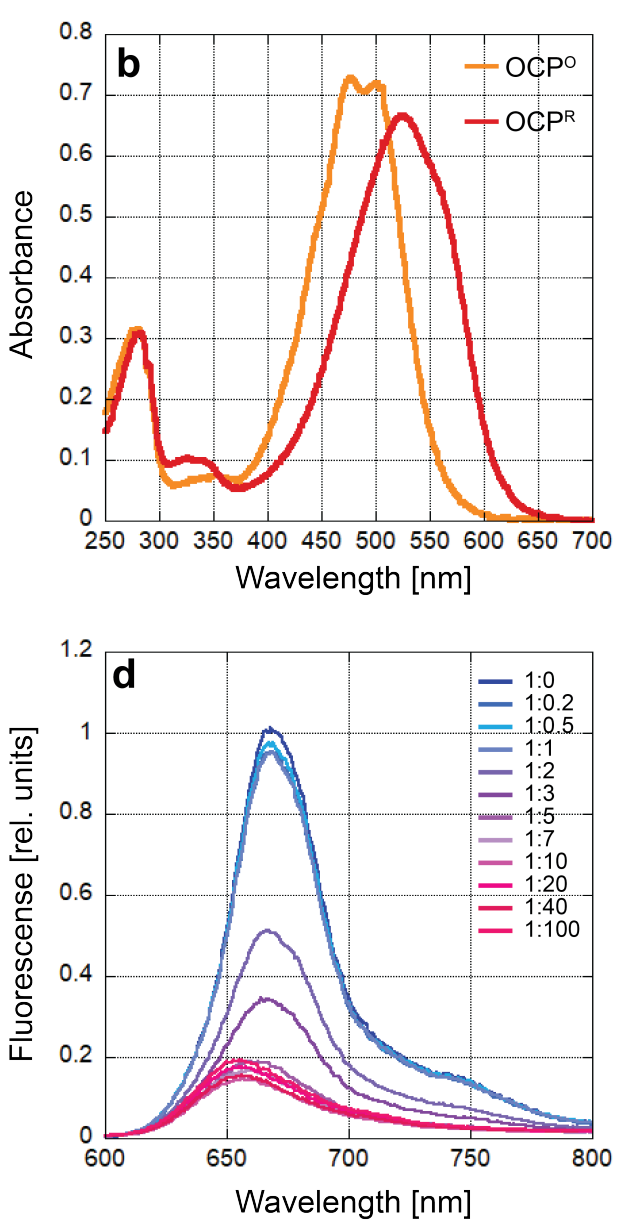

495 Extended Data Fig. 4: Synechocystis PCC 6803 OCP Purification. a, Coomassie blue-stained SDS-PAGE. b, UV-Vis 496 absorption spectra of the $\mathrm{OCP}^{\mathrm{O}}$ (inactive form) and $\mathrm{OCP}^{\mathrm{R}}$ (active form). c, Fluorescence quenching of 1:20 (PBS:OCP). 497 The PBS is biotinylated. d, Titration PBS:OCP fluorescence quenching at various ratios indicated. 
bioRxiv preprint doi: https://doi org/10.1101/2021.11.15.468719; this version posted November 15,2021 . The copyright holder for this preprint (which was not certified by peer review) is the author/funder, who has granted bioRxiv a license to display the preprint in perpetuity. It is made available under aCC-BY-NC-ND 4.0 International license.

OCP-Phycobilisome Paper
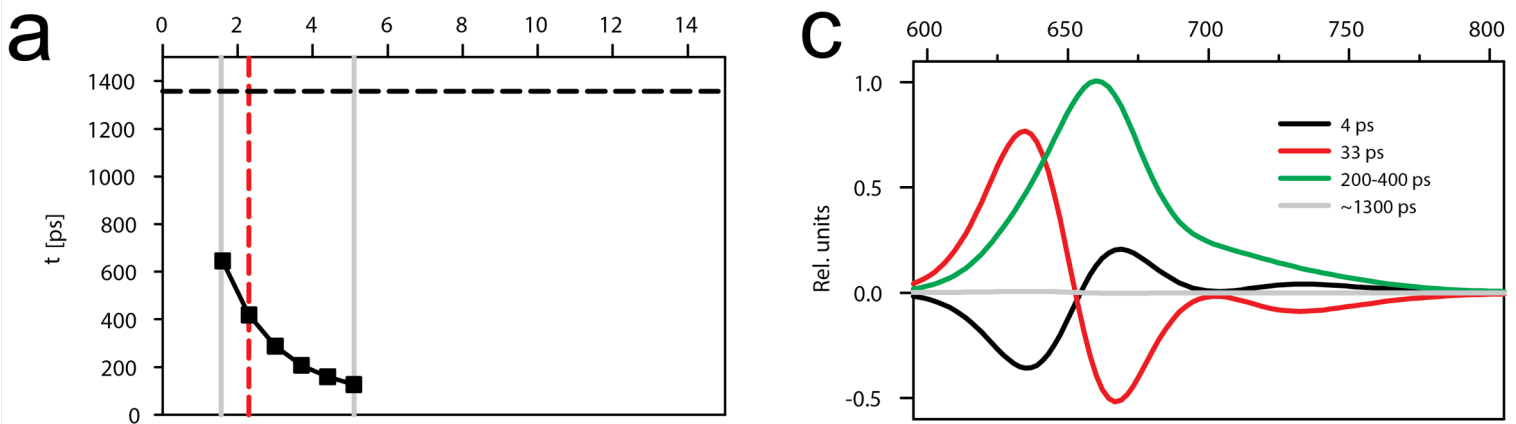

b
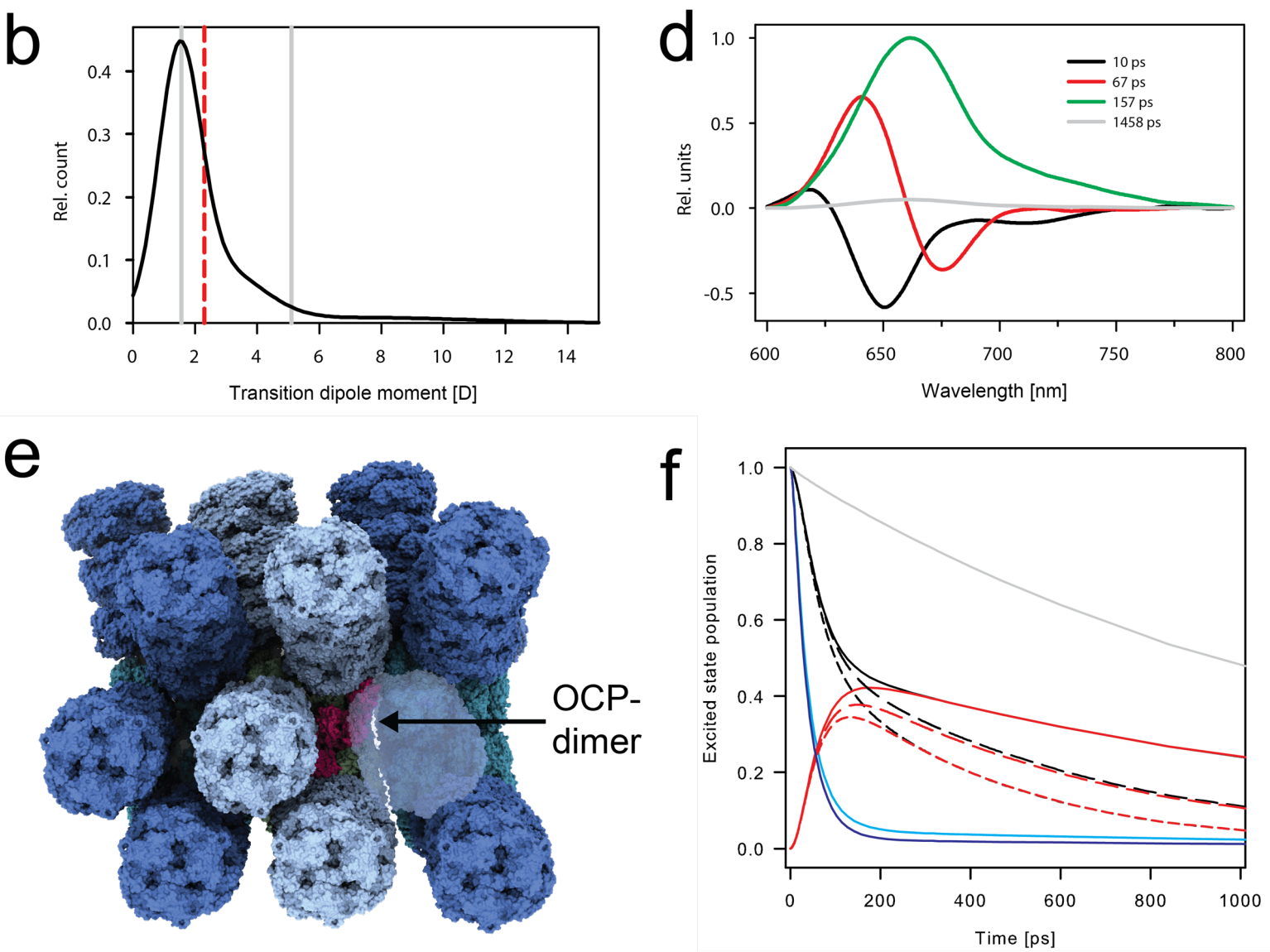

501 Extended Data Fig. 5. a, Effect of the transition dipole moment (TDM) of canthaxanthin in OCP on the lifetime of excitation in PBS; the dashed line indicates the lifetime of unquenched PBS (TDM =0); $\mathbf{b}$, Distribution of TDM values of echinenone in OCP, adapted from ${ }^{44}$. The red line indicates the mean value, $2.3 \mathrm{D}$; the range marked by grey lines is used for simulations shown in panel (a). c, Decay associated spectra obtained from a simulation based on the OCP-PBS structure. It represents the excitation energy flow in the fully quenched OCP-PBS after excitation into the far end of the rod. The value of the green component, corresponding to the quenching, depends on the TDM value shown in panel (a). d, The same spectra obtained from fitting the time-resolved fluorescence data (adapted from ${ }^{29}$ ). e, PBS array with OCP bound. OCP 
bioRxiv preprint doi: https://doi org/10.1101/2021.11 15.468719; this version posted November 15,2021 . The copyright holder for this

preprint (which was not certified by peer review) is the author/funder, who has granted bioRxiv a license to display the preprint in perpetuity. It is made available under aCC-BY-NC-ND 4.0 International license.

OCP-Phycobilisome Paper

509 after excitation into the outer tip of the PBS1 bottom rod. Cyan (single PBS) and blue (PBS pair) kinetics monitors

510 population in the rod. Grey, black and red lines represent excitation summed over all bilins in the PBS. Grey line shows

511 the total excitation in a single PBS without OCP; In the PBS pair, the excitation is distributed from the initially excited

512 PBS1 (black) to PBS2(red). Solid line, PBS pair without OCP; short dash, each PBS binds 4 OCPs; long-dash PBS2 binds

5134 OCPs, PBS1 has no OCP. This simulation shows that the effect of OCP is shared between PBS in the pair. Analysis of

514 transfer times suggested less than 20 inter-PBS bilin pairs with transfer times shorter than 20 ps. Majority of those were in

515 the top cylinder of the core. Several close contacts were also identified between rods, however, the comparison of the blue

516 and cyan traces shows that arranging PBS into a pair has little effect on the excitation dynamics within a rod.

517
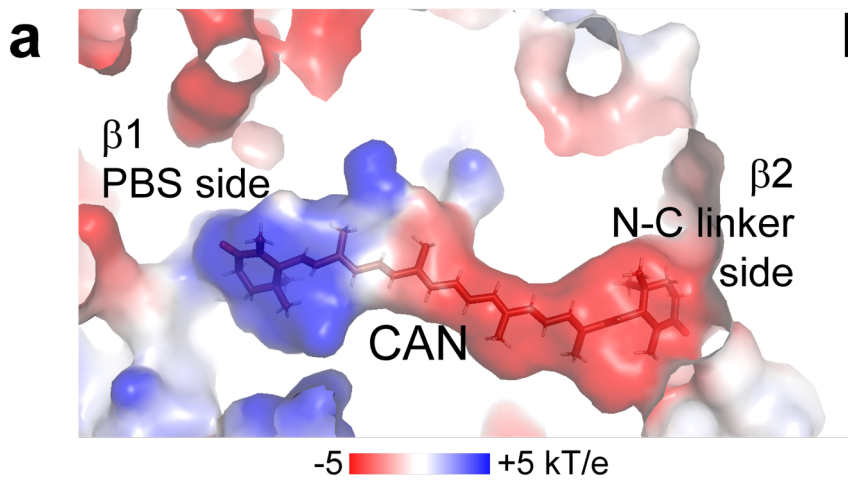

b

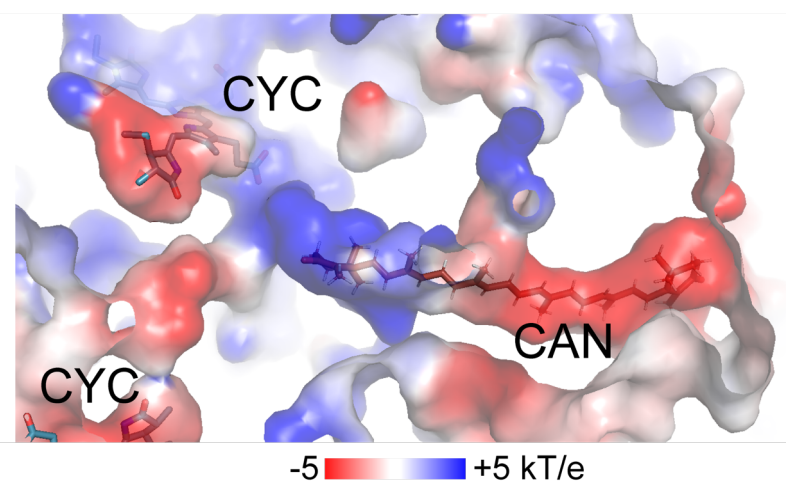

519 Extended Data Fig. 6: Electrostatics of the protein environment of the carotenoid tunnel mapped on the $\mathbf{O C P}^{\mathrm{R}}$

520 bound to the PBS. a, Carotenoid tunnel with the $\beta 1$ and $\beta 2$ indicated and carotenoid shown as sticks. b, Electrostatic 521 surfaces of the proteins around the carotenoid tunnel and the nearby bilins; carotenoid and bilins shown as sticks. 
bioRxiv preprint doi: https://doi org/10.1101/2021.11.15.468719 this version posted November 15,2021 . The copyright holder for this preprint (which was not certified by peer review) is the author/funder, who has granted bioRxiv a license to display the preprint in perpetuity. It is made available under aCC-BY-NC-ND 4.0 International license.

a

\begin{tabular}{cc}
\hline CTD (A) & CTD (B) \\
\hline $220 \mathrm{ASP}$ & \\
$224 \mathrm{GLN}$ & $224 \mathrm{GLN}$ \\
$227 \mathrm{PHE}$ & $227 \mathrm{PHE}$ \\
$228 \mathrm{GLN}$ & $228 \mathrm{GLN}$ \\
$229 \mathrm{ARG}$ & $229 \mathrm{ARG}$ \\
230 PRO & $230 \mathrm{PRO}$ \\
232 VAL & $231 \mathrm{ILE}$ \\
261 GLU & $232 \mathrm{VAL}$ \\
278 PHE & $239 \mathrm{ARG}$ \\
289 ARG & $240 \mathrm{PHE}$ \\
291 LEU & $262 \mathrm{ASP}$ \\
299 PHE & $264 \mathrm{PHE}$ \\
306 LEU & $289 \mathrm{ARG}$ \\
307 ALA & $300 \mathrm{PHE}$ \\
309 PRO & $306 \mathrm{LEU}$ \\
311 GLU & $307 \mathrm{ALA}$ \\
313 LEU & $309 \mathrm{PRO}$ \\
314 ASN & 311 GLU \\
315 PHE & \\
316 ALA & \\
317 ARG & \\
\hline
\end{tabular}

b

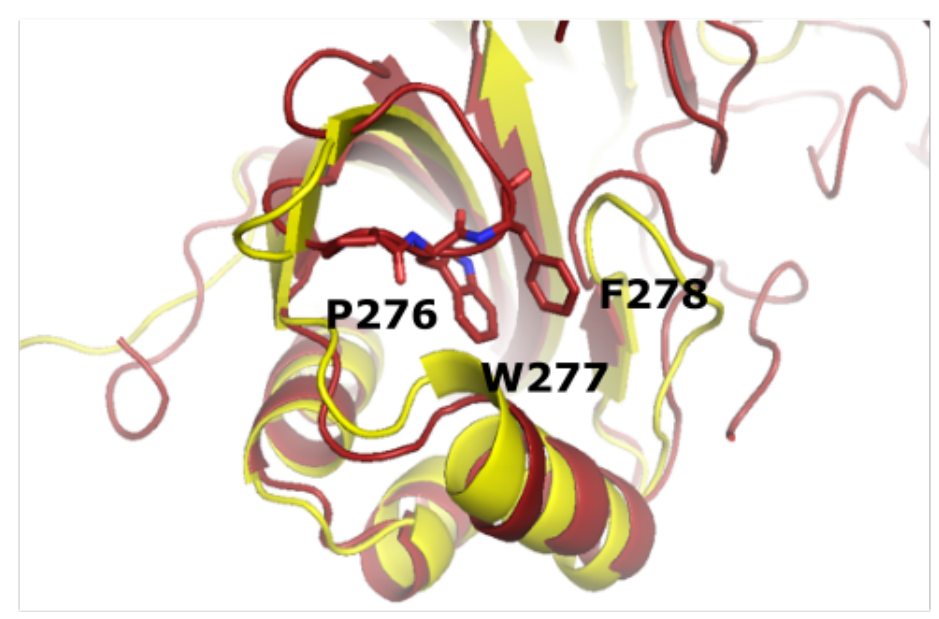

C
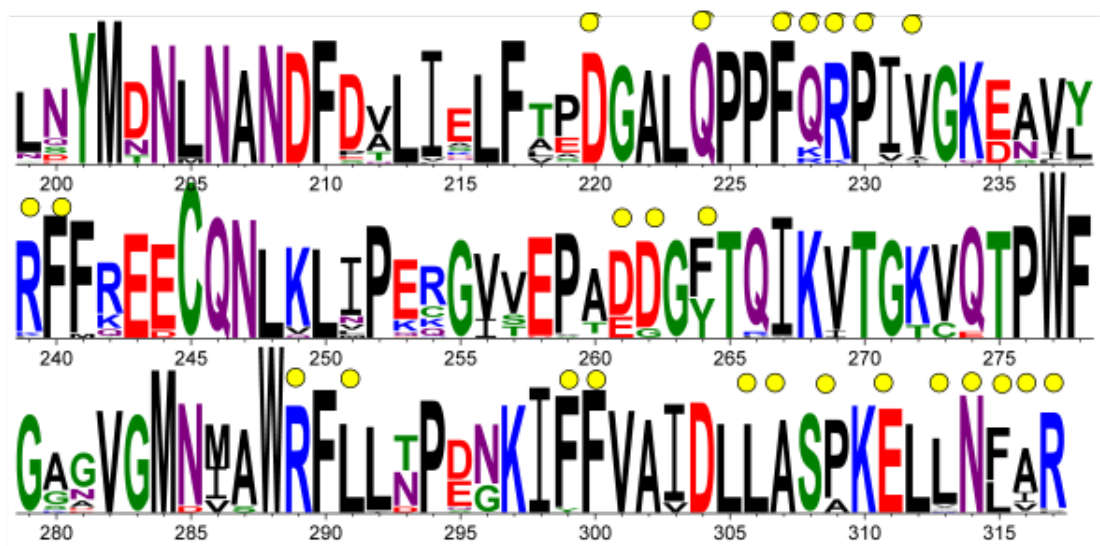

525 Extended data Fig. 7: CTD from OCP. a, List of residues that interact within $4 \AA$. b, Close-up view of the P276-

526 W277-F278 loop covering the opening to the carotenoid tunnel in the CTD of $\mathrm{OCP}^{\mathrm{O}}$. $\mathbf{c}$, Sequence conservation logo for the CTD (beginning at residue 199) of the OCP. Residues involved in the dimerization are highlighted with a yellow dot. 


\section{Extended Data Table 1: Cryo-EM data collection, refinement and validation statistics}

\begin{tabular}{|c|c|c|c|c|c|c|c|}
\hline & $\begin{array}{l}\text { PBS-OCP } \\
\text { (EMDB- } \\
25068)\end{array}$ & $\begin{array}{l}\text { Core } \\
\text { (EMDB- } \\
25030) \\
\text { (PDB } \\
7 \text { SC9) }\end{array}$ & $\begin{array}{l}\text { B-cylinder } \\
\text { (EMDB- } \\
25032) \\
\text { (PDB } \\
7 \mathrm{SCB})\end{array}$ & $\begin{array}{l}\text { T-cylinder } \\
\text { (EMDB- } \\
\text { 25033) } \\
\text { (PDB } \\
7 \text { SCC) }\end{array}$ & $\begin{array}{l}\text { T-disc } 1 \\
\text { (EMDB- } \\
25068)\end{array}$ & $\begin{array}{l}\text { T-disc } 2 \\
\text { (EMDB- } \\
25068)\end{array}$ & $\begin{array}{l}\text { Rod } \\
\text { (EMDB-25031) } \\
\text { (PDB 7SCA) }\end{array}$ \\
\hline $\begin{array}{l}\text { Data collection and } \\
\text { processing }\end{array}$ & & & & & & & \\
\hline Magnification & \multirow{2}{*}{\multicolumn{7}{|c|}{$\begin{array}{c}81000 \mathrm{x} \\
300\end{array}$}} \\
\hline Voltage $(\mathrm{kV})$ & & & & & & & \\
\hline $\begin{array}{l}\text { Electron exposure (e- } \\
\left./ \AA^{2}\right)\end{array}$ & \multicolumn{7}{|c|}{50} \\
\hline Defocus range $(\mu \mathrm{m})$ & \multicolumn{7}{|c|}{$0.5-1.6$} \\
\hline Pixel size $(\AA)$ & \multicolumn{7}{|c|}{1.05} \\
\hline Symmetry imposed & \multicolumn{7}{|c|}{$\mathrm{C} 1$} \\
\hline $\begin{array}{l}\text { Initial particle images } \\
\text { (no.) }\end{array}$ & \multicolumn{6}{|c|}{$2.5 \mathrm{M}$} & $5.2 \mathrm{M}$ \\
\hline $\begin{array}{l}\text { Final particle images } \\
\text { (no.) }\end{array}$ & 338,725 & \multicolumn{5}{|c|}{340,839} & $2.1 \mathrm{M}$ \\
\hline $\begin{array}{l}\text { Map resolution }(\AA) \\
\text { FSC threshold }\end{array}$ & 2.7 & 2.6 & 2.5 & 2.7 & 2.6 & 2.8 & 2.1 \\
\hline 0.143 & & & & & & & \\
\hline $\begin{array}{l}\text { Map resolution range } \\
(\AA)\end{array}$ & $2.5-10$ & $2.4-10$ & $2.3-3.5$ & $2.5-4$ & $2.4-4$ & $2.6-5$ & $2.1-2.5$ \\
\hline Refinement & & & & & & & \\
\hline Initial model used & & B- and & $4 \mathrm{~F} 0 \mathrm{~T}$ & $4 \mathrm{~F} 0 \mathrm{~T}$ & & & 4F0T, 5Y6P, \\
\hline (PDB code) & & T-cylinder & $\begin{array}{l}5 \mathrm{Y} 6 \mathrm{P} \\
6 \mathrm{KGX}\end{array}$ & $\begin{array}{l}5 \mathrm{Y} 6 \mathrm{P} \\
6 \mathrm{KGX}\end{array}$ & & & $6 \mathrm{KGX}$ \\
\hline $\begin{array}{c}\text { Model resolution }(\AA) \\
\text { FSC threshold } 0.5\end{array}$ & & 3.1 & 2.8 & 3.2 & & & 2.3 \\
\hline Model composition & & & & & & & \\
\hline Non-hydrogen & & 117470 & 37281 & 43008 & & & 54106 \\
\hline atoms & & 14948 & 4743 & 5474 & & & 6835 \\
\hline Protein residues & & 76 & 25 & 26 & & & 54 \\
\hline$B$ factors $\left(\AA^{2}\right)$ & & & & & & & \\
\hline Protein & & 128.56 & 128.27 & 113.96 & & & 97.47 \\
\hline Ligand & & 117.94 & 124.22 & 94.94 & & & 96.46 \\
\hline R.m.s. deviations & & & & & & & \\
\hline Bond lengths $(\AA)$ & & $0.004(1)$ & $0.002(0)$ & $0.002(0)$ & & & $0.002(0)$ \\
\hline Bond angles $\left(^{\circ}\right)$ & & $0.562(82)$ & $0.427(18)$ & $0.443(13)$ & & & $0.802(12)$ \\
\hline Validation & & & & & & & \\
\hline MolProbity score & & 2.43 & 2.17 & 2.38 & & & 1.56 \\
\hline Clashscore & & 56.86 & 42.51 & 51.58 & & & 11.03 \\
\hline Poor rotamers $(\%)$ & & 0.03 & 0.00 & 0.00 & & & 0.00 \\
\hline Ramachandran plot & & & & & & & \\
\hline Favored (\%) & & 96.75 & 97.69 & 96.85 & & & 98.79 \\
\hline Allowed (\%) & & 3.20 & 2.26 & 3.08 & & & 1.21 \\
\hline Disallowed (\%) & & 0.05 & 0.04 & 0.07 & & & 0.00 \\
\hline
\end{tabular}


bioRxiv preprint doi: https://doi org/10.1101/2021.11.15.468719; this version posted November 15, 2021. The copyright holder for this preprint (which was not certified by peer review) is the author/funder, who has granted bioRxiv a license to display the preprint in perpetuity. It is made available under aCC-BY-NC-ND 4.0 International license.

OCP-Phycobilisome Paper

Extended Data Table 2: Pairwise interactions within $4 \AA$ between the OCP and the B cylinders.

\begin{tabular}{|c|c|c|c|}
\hline $\begin{array}{c}\text { ОСР } \\
\text { Residue }\end{array}$ & $\begin{array}{c}\text { PBS } \\
\text { Residue }\end{array}$ & Trimer/protein & Chain \\
\hline \multirow[t]{2}{*}{ Gly10 } & Tyr62 & b23 & $\mathrm{D}(\mathrm{ApcB})$ \\
\hline & Ala57 & b23 & $\mathrm{D}(\mathrm{ApcB})$ \\
\hline \multirow[t]{3}{*}{ Ile11 } & Glu76 & b23 & $E($ ApcA) \\
\hline & Met77 & b23 & $E(A p c A)$ \\
\hline & Tyr62 & b23 & $\mathrm{D}(\mathrm{ApcB})$ \\
\hline \multirow[t]{5}{*}{ Phe12 } & Tyr62 & b23 & $\mathrm{D}(\mathrm{ApcB})$ \\
\hline & Glu76 & b23 & $E(A p c A)$ \\
\hline & Thr80 & b23 & $E(A p c A)$ \\
\hline & Pro215 & cpcg1 & \\
\hline & Met216 & cpcg1 & \\
\hline \multirow[t]{2}{*}{ Asn14 } & Leu219 & cpcg1 & \\
\hline & Arg223 & cpcg1 & \\
\hline Asp19 & Arg223 & cpcg1 & \\
\hline Pro22 & Arg223 & cpcg1 & \\
\hline Thr52 & Tyr73 & b23 & $E(A p c A)$ \\
\hline \multirow[t]{2}{*}{ Ile53 } & Pro68 & b23 & $E(A p c A)$ \\
\hline & Pro63 & b24 & $E(A p c A)$ \\
\hline Ala54 & $\mathrm{Gln} 60$ & b24 & $E(A p c A)$ \\
\hline \multirow[t]{4}{*}{ Ala55 } & Gly69 & b23 & $E(A p c A)$ \\
\hline & Pro68 & b23 & $E(A p c A)$ \\
\hline & Lys61 & b24 & $E(A p c A)$ \\
\hline & Pro63 & b24 & $E(A p c A)$ \\
\hline Pro56 & Lys61 & b24 & $E(A p c A)$ \\
\hline \multirow[t]{2}{*}{ Gly57 } & Lys61 & b24 & $E(A p c A)$ \\
\hline & Arg62 & b24 & $E(A p c A)$ \\
\hline \multirow[t]{2}{*}{ Ala58 } & Gly69 & b23 & $E(A p c A)$ \\
\hline & Arg62 & b24 & $E(A p c A)$ \\
\hline \multirow[t]{2}{*}{ Ser60 } & Thr50 & b23 & $\mathrm{D}(\mathrm{ApcB})$ \\
\hline & Glu54 & b23 & $\mathrm{D}(\mathrm{ApcB})$ \\
\hline \multirow[t]{3}{*}{ Gln62 } & Thr50 & b23 & $D(A p c B)$ \\
\hline & Leu140 & b23 & $D(\mathrm{ApcB})$ \\
\hline & Arg131 & b24 & $E(A p c A)$ \\
\hline \multirow[t]{4}{*}{ Leu63 } & Glu54 & b23 & D (ApcB) \\
\hline & Val136 & b23 & $\mathrm{D}(\mathrm{ApcB})$ \\
\hline & Ser139 & b23 & $\mathrm{D}(\mathrm{ApcB})$ \\
\hline & Leu140 & b23 & $\mathrm{D}(\mathrm{ApcB})$ \\
\hline Asn66 & Ser139 & b23 & $\mathrm{D}(\mathrm{ApcB})$ \\
\hline Ser100 & Lys58 & b23 & $\mathrm{D}(\mathrm{ApcB})$ \\
\hline Ser102 & Glu54 & b23 & $\mathrm{D}(\mathrm{ApcB})$ \\
\hline Ile105 & Glu54 & b23 & $\mathrm{D}(\mathrm{ApcB})$ \\
\hline \multirow[t]{2}{*}{ Ser147 } & Tyr73 & b23 & $E(A p c A)$ \\
\hline & Ala229 & cpcg1 & \\
\hline \multirow[t]{3}{*}{ Gly148 } & Tyr73 & b23 & $E(A p c A)$ \\
\hline & Gly74 & b23 & $E(A p c A)$ \\
\hline & Glu75 & b23 & $E(A p c A)$ \\
\hline Gln149 & Glu75 & b23 & $E(A p c A)$ \\
\hline \multirow[t]{2}{*}{ IIE151 } & Tyr73 & b23 & $E(A p c A)$ \\
\hline & Gly74 & b23 & $E(A p c A)$ \\
\hline \multirow[t]{3}{*}{ Thr152 } & Gly74 & b23 & $E(A p c A)$ \\
\hline & Glu75 & b23 & $E(A p c A)$ \\
\hline & Glu76 & b23 & $E(A p c A)$ \\
\hline \multirow[t]{2}{*}{ Arg155 } & Tyr73 & b23 & $E(A p c A)$ \\
\hline & Glu76 & b23 & $E(A p c A)$ \\
\hline Ala165 & Asp25 & b22 & B (ApcB) \\
\hline \multirow[t]{2}{*}{ Gly166 } & Gly21 & b22 & $\mathrm{B}(\mathrm{ApcB})$ \\
\hline & Asp25 & b22 & $\mathrm{B}(\mathrm{ApcB})$ \\
\hline CAN & Pro68 & b23 & $E(A p c A)$ \\
\hline & Gly69 & b23 & $E(A p c A)$ \\
\hline & Gly70 & b23 & $E(A p c A)$ \\
\hline & Tyr73 & b23 & $E(A p c A)$ \\
\hline
\end{tabular}


bioRxiv preprint doi: https://doi.org/10.1101/2021.11.15.468719; this version posted November $15,2021$. The copyright holder for this preprint (which was not certified by peer review) is the author/funder, who has granted bioRxiv a license to display the preprint in perpetuity. It is made available under aCC-BY-NC-ND 4.0 International license.

OCP-Phycobilisome Paper

535 Extended Data Table 3: Pairwise interactions within $4 \AA$ between the OCP and the Top cylinders

(Ta, left; Tb right).

\begin{tabular}{|c|c|c|c|}
\hline $\begin{array}{c}\text { OCP } \\
\text { Residue }\end{array}$ & $\begin{array}{c}\text { PBS } \\
\text { Residue }\end{array}$ & Trimer/Protein & Chain \\
\hline \multirow[t]{2}{*}{ Thr52 } & Pro68 & Ta1 & $A(A p c A)$ \\
\hline & Tyr73 & Ta1 & $A(A p c A)$ \\
\hline Ile53 & Pro68 & Ta1 & $A(A p c A)$ \\
\hline Ala54 & Gln60 & $\mathrm{Ta} 2$ & $C(A p c A)$ \\
\hline \multirow[t]{3}{*}{ Ala55 } & Gly69 & ta1 & $A(A p c A)$ \\
\hline & Lys61 & ta2 & $C(\mathrm{Apc} A)$ \\
\hline & Pro63 & ta2 & $C(A p c A)$ \\
\hline \multirow[t]{2}{*}{ Pro56 } & Gln60 & ta2 & $C(\mathrm{ApcA})$ \\
\hline & Lys61 & ta2 & $C(\mathrm{ApcA})$ \\
\hline \multirow[t]{3}{*}{ Gly57 } & Lys61 & ta2 & $C(\mathrm{ApcA})$ \\
\hline & Arg62 & ta2 & $C(A p c A)$ \\
\hline & $\mathrm{G} \ln 128$ & ta2 & $C(\mathrm{Apc} A)$ \\
\hline \multirow[t]{3}{*}{ Ala58 } & Gly69 & ta1 & $A(A p c A)$ \\
\hline & Lys61 & ta2 & $C(A p c A)$ \\
\hline & Arg62 & ta2 & $C(\mathrm{Apc} A)$ \\
\hline \multirow[t]{2}{*}{ Ser60 } & Thr50 & ta1 & $F(A p c B)$ \\
\hline & Glu54 & ta1 & $F(A p c B)$ \\
\hline \multirow[t]{4}{*}{ Gln62 } & Asn47 & ta1 & $F(A p c B)$ \\
\hline & Thr50 & ta1 & $F(A p c B)$ \\
\hline & Leu140 & ta 1 & $F(A p c B)$ \\
\hline & Arg131 & ta2 & $C(A p c A)$ \\
\hline \multirow[t]{4}{*}{ Leu63 } & Thr50 & ta1 & $F(A p c B)$ \\
\hline & Glu54 & ta 1 & $F(A p c B)$ \\
\hline & Val136 & ta1 & $F(A p c B)$ \\
\hline & Leu140 & ta1 & $F(A p c B)$ \\
\hline \multirow[t]{3}{*}{ Asn66 } & Ser139 & ta1 & $F(A p c B)$ \\
\hline & Leu140 & ta 1 & $F(A p c B)$ \\
\hline & Gly142 & ta1 & $F(A p c B)$ \\
\hline Thr97 & Ser139 & ta1 & $F(A p c B)$ \\
\hline \multirow[t]{2}{*}{ Ser100 } & Lys58 & ta1 & $F(A p c B)$ \\
\hline & Ser139 & ta1 & $F(A p c B)$ \\
\hline Trp101 & Ser139 & ta1 & $F(A p c B)$ \\
\hline Ser102 & Glu54 & ta1 & $F(A p c B)$ \\
\hline Pro103 & Arg249 & cpcg1 & \\
\hline Ile105 & Glu54 & ta1 & $F(A p c B)$ \\
\hline Glu146 & Lys234 & cpcg1 & \\
\hline Ser147 & Tyr73 & ta1 & $A(A p c A)$ \\
\hline \multirow[t]{2}{*}{ Gly148 } & Gly74 & ta1 & $A(A p c A)$ \\
\hline & Glu75 & ta1 & $A(A p c A)$ \\
\hline \multirow[t]{2}{*}{ Ile151 } & Tyr73 & ta1 & $A(A p c A)$ \\
\hline & Gly74 & ta1 & $A(A p c A)$ \\
\hline \multirow[t]{3}{*}{ Thr152 } & Gly74 & ta1 & $A(A p c A)$ \\
\hline & Glu75 & ta1 & $A(A p c A)$ \\
\hline & Glu76 & ta1 & $A(A p c A)$ \\
\hline \multirow[t]{3}{*}{ Arg155 } & Tyr73 & ta1 & $A(A p c A)$ \\
\hline & Gly74 & ta1 & $A(A p c A)$ \\
\hline & Met77 & ta1 & $A(A p c A)$ \\
\hline Asn314 & Leu140 & ta2 & $C(\mathrm{ApcA})$ \\
\hline \multirow{2}{*}{ Phe315 } & Gly139 & ta2 & $C(\mathrm{ApcA})$ \\
\hline & Leu140 & ta2 & $C(\mathrm{ApcA})$ \\
\hline Arg317 & Thr42 & ta2 & $C(\mathrm{ApcA})$ \\
\hline \multirow[t]{4}{*}{ CAN } & Pro68 & ta1 & $\mathrm{A}(\mathrm{ApcA})$ \\
\hline & Gly69 & ta1 & $A(A p c A)$ \\
\hline & Gly70 & ta1 & $A(A p c A)$ \\
\hline & Tyr73 & ta1 & $A(A p c A)$ \\
\hline
\end{tabular}

\begin{tabular}{|c|c|c|c|}
\hline $\begin{array}{c}\text { OCP } \\
\text { Residue }\end{array}$ & $\begin{array}{c}\text { PBS } \\
\text { Residue }\end{array}$ & Trimer/Protein & Chain \\
\hline Val21 & Glu75 & $\mathrm{Tb} 1$ & $A(A p c A)$ \\
\hline \multirow[t]{2}{*}{ Thr52 } & Pro68 & tb1 & $A(A p c A)$ \\
\hline & Tyr73 & tb1 & $A(A p c A)$ \\
\hline \multirow[t]{2}{*}{ Ile53 } & Pro68 & Tb1 & $A(A p c A)$ \\
\hline & Asn230 & cpcg1 & \\
\hline Ala54 & $\mathrm{G} \ln 60$ & tb2 & $C(\mathrm{Apc} A)$ \\
\hline \multirow[t]{3}{*}{ Ala55 } & Gly69 & tb1 & $A(A p c A)$ \\
\hline & Lys61 & tb2 & $C(\mathrm{ApcA})$ \\
\hline & Pro63 & tb2 & $C($ ApcA) \\
\hline Pro56 & Lys61 & tb2 & $C($ ApcA) \\
\hline \multirow[t]{3}{*}{ Gly57 } & Lys61 & tb2 & $C($ ApcA) \\
\hline & Arg62 & tb2 & $C($ ApcA) \\
\hline & Gln128 & tb2 & $C(\mathrm{ApcA})$ \\
\hline \multirow[t]{3}{*}{ Ala58 } & Gly69 & tb1 & $A(A p c A)$ \\
\hline & Lys61 & tb2 & $C(A p c A)$ \\
\hline & Arg62 & tb2 & $C(\mathrm{ApcA})$ \\
\hline \multirow[t]{2}{*}{ Ser60 } & Thr50 & tb1 & $F(A p c B)$ \\
\hline & Glu54 & tb1 & $F(A p c B)$ \\
\hline \multirow[t]{4}{*}{ Gln62 } & Asn47 & tb1 & $F(\mathrm{ApcB})$ \\
\hline & Thr50 & tb1 & $F(A p c B)$ \\
\hline & Leu140 & tb1 & $F(A p c B)$ \\
\hline & Arg131 & tb2 & $C($ ApcA) \\
\hline \multirow[t]{3}{*}{ Leu63 } & Glu54 & tb1 & $F(A p c B)$ \\
\hline & Ser139 & tb1 & $F(A p c B)$ \\
\hline & Leu140 & tb1 & $F(A p c B)$ \\
\hline \multirow[t]{3}{*}{ Asn66 } & Ser139 & tb1 & $F(A p c B)$ \\
\hline & Leu140 & tb1 & $F(A p c B)$ \\
\hline & Gly142 & tb1 & $F(A p c B)$ \\
\hline Thr97 & Ser139 & tb1 & $F(A p c B)$ \\
\hline \multirow[t]{2}{*}{ Ser100 } & Lys58 & tb1 & $F(\mathrm{ApcB})$ \\
\hline & Glu135 & tb1 & $F(A p c B)$ \\
\hline Trp101 & Ser139 & tb1 & $F(A p c B)$ \\
\hline Ser102 & Glu54 & tb1 & $F(A p c B)$ \\
\hline Ile105 & Glu54 & tb1 & $F(\mathrm{ApcB})$ \\
\hline \multirow{2}{*}{ Glu146 } & Lys234 & cpcg1 & \\
\hline & Val235 & cpcg1 & \\
\hline Ser147 & Tyr73 & tb1 & $A(A p c A)$ \\
\hline \multirow[t]{2}{*}{ Gly148 } & Gly74 & tb1 & $A(A p c A)$ \\
\hline & Glu75 & tb1 & $A(A p c A)$ \\
\hline \multirow[t]{2}{*}{ Ile151 } & Tyr73 & tb1 & $A(A p c A)$ \\
\hline & Gly74 & tb1 & $A(A p c A)$ \\
\hline \multirow[t]{3}{*}{ Thr152 } & Gly74 & tb1 & $A(A p c A)$ \\
\hline & Glu75 & tb1 & $A(A p c A)$ \\
\hline & Glu76 & tb1 & $A(A p c A)$ \\
\hline \multirow[t]{3}{*}{ Arg155 } & Tyr73 & tb1 & $A(A p c A)$ \\
\hline & Glu76 & tb1 & $A(A p c A)$ \\
\hline & Met77 & tb1 & $A(A p c A)$ \\
\hline Asn314 & Gly139 & tb2 & $C(\mathrm{ApcA})$ \\
\hline \multirow[t]{2}{*}{ Phe315 } & Gly139 & tb2 & $C($ ApcA) \\
\hline & Leu140 & tb2 & $C(\mathrm{ApcA})$ \\
\hline Arg317 & Thr42 & tb2 & $C(\mathrm{Apc} A)$ \\
\hline \multirow[t]{4}{*}{ CAN } & Pro68 & tb1 & $A(A p c A)$ \\
\hline & Gly69 & tb1 & $A(A p c A)$ \\
\hline & Gly70 & tb1 & $A(A p c A)$ \\
\hline & Tyr73 & tb1 & $A(A p c A)$ \\
\hline
\end{tabular}


bioRxiv preprint doi: https://doi.org/10.1101/2021.11.15.468719; this version posted November 15, 2021. The copyright holder for this

preprint (which was not certified by peer review) is the author/funder, who has granted bioRxiv a license to display the preprint in perpetuity. It is made available under aCC-BY-NC-ND 4.0 International license.

OCP-Phycobilisome Paper

\section{Supplementary Information}

540

Supplementary video 1: Display of the CTD displacement and carotenoid translocation in $\mathbf{O C P}^{\mathbf{R}}$. NTD $=$ N-terminal domain, CTD $=$ C-terminal domain, NTE $=$ N-terminal extension. The carotenoid appears in sphere representation. $\beta 1$ and $\beta 2$ surfaces are labeled as well. 
OCP-Phycobilisome Paper

\section{References}

5651 Niyogi, K. K. \& Truong, T. B. Evolution of flexible non-photochemical quenching mechanisms that regulate light harvesting in oxygenic photosynthesis. Curr Opin Plant Biol 16, 307-314, doi:10.1016/j.pbi.2013.03.011 (2013).

2 Melis, A. Solar energy conversion efficiencies in photosynthesis: Minimizing the chlorophyll antennae to maximize efficiency. Plant Sci 177, 272-280, doi:10.1016/j.plantsci.2009.06.005 (2009).

3 Wilson, A. et al. A photoactive carotenoid protein acting as light intensity sensor. Proc Natl Acad Sci U S A 105, 12075-12080, doi:10.1073/pnas.0804636105 (2008).

4 Kerfeld, C. A., Melnicki, M. R., Sutter, M. \& Dominguez-Martin, M. A. Structure, function and evolution of the cyanobacterial orange carotenoid protein and its homologs. New Phytol 215, 937-951, doi:10.1111/nph.14670 (2017).

5 Kirilovsky, D. \& Kerfeld, C. A. Cyanobacterial photoprotection by the orange carotenoid protein. Nat Plants 2, 16180, doi:10.1038/nplants.2016.180 (2016).

6 Kerfeld, C. A. et al. The crystal structure of a cyanobacterial water-soluble carotenoid binding protein. Structure 11, 55-65, doi:10.1016/s0969-2126(02)00936-x (2003).

5807 Wilson, A. et al. A soluble carotenoid protein involved in phycobilisome-related energy dissipation in cyanobacteria. Plant Cell 18, 992-1007, doi:10.1105/tpc.105.040121 (2006).

8 Gwizdala, M., Wilson, A. \& Kirilovsky, D. In vitro reconstitution of the cyanobacterial photoprotective mechanism mediated by the Orange Carotenoid Protein in Synechocystis PCC 6803. Plant Cell 23, 2631-2643, doi:10.1105/tpc.111.086884 (2011).

5859 Leverenz, R. L. et al. PHOTOSYNTHESIS. A 12 A carotenoid translocation in a photoswitch associated with cyanobacterial photoprotection. Science 348, 1463-1466, doi:10.1126/science.aaa7234 (2015).

10 Leverenz, R. L. et al. Structural and functional modularity of the orange carotenoid protein: distinct roles for the $\mathrm{N}$ - and $\mathrm{C}$-terminal domains in cyanobacterial photoprotection. Plant Cell

26, 426-437, doi:10.1105/tpc.113.118588 (2014).

11 Sauer, P. et al. Structures of the cyanobacterial phycobilisome. Submitted (2021).

12 Squires, A. H. et al. Single-molecule trapping and spectroscopy reveals photophysical heterogeneity of phycobilisomes quenched by Orange Carotenoid Protein. Nat Commun 10, doi:ARTN 117210.1038/s41467-019-09084-2 (2019).

59513 Rast, A. et al. Biogenic regions of cyanobacterial thylakoids form contact sites with the plasma membrane. Nat Plants 5, 436-446, doi:10.1038/s41477-019-0399-7 (2019).

14 Gupta, S. et al. Local and global structural drivers for the photoactivation of the orange carotenoid protein. Proc Natl Acad Sci U S A 112, E5567-5574, doi:10.1073/pnas. 1512240112 (2015).

60015 Bao, H. et al. Additional families of orange carotenoid proteins in the photoprotective system of cyanobacteria. Nat Plants 3, 17089, doi:10.1038/nplants.2017.89 (2017).

16 Sutter, M. et al. Crystal structure of the FRP and identification of the active site for modulation of OCP-mediated photoprotection in cyanobacteria. Proc Natl Acad Sci U S A 110, 1002210027, doi:10.1073/pnas.1303673110 (2013).

60517 Boulay, C., Wilson, A., D'Haene, S. \& Kirilovsky, D. Identification of a protein required for recovery of full antenna capacity in OCP-related photoprotective mechanism in cyanobacteria. Proc Natl Acad Sci U S A 107, 11620-11625, doi:10.1073/pnas.1002912107 (2010).

18 Sluchanko, N. N. et al. OCP-FRP protein complex topologies suggest a mechanism for controlling high light tolerance in cyanobacteria. Nat Commun 9, 3869, doi:10.1038/s41467018-06195-0 (2018). 
bioRxiv preprint doi: https://doi.org/10.1101/2021.11.15.468719; this version posted November $15,2021$. The copyright holder for this preprint (which was not certified by peer review) is the author/funder, who has granted bioRxiv a license to display the preprint in perpetuity. It is made available under aCC-BY-NC-ND 4.0 International license.

OCP-Phycobilisome Paper

19 Gupta, S. et al. X-ray radiolytic labeling reveals the molecular basis of orange carotenoid protein photoprotection and its interactions with fluorescence recovery protein. $J$ Biol Chem 294, 8848-8860, doi:10.1074/jbc.RA119.007592 (2019).

20 Zhang, H. et al. Molecular mechanism of photoactivation and structural location of the cyanobacterial orange carotenoid protein. Biochemistry 53, 13-19, doi:10.1021/bi401539w (2014).

21 Harris, D. et al. Orange carotenoid protein burrows into the phycobilisome to provide photoprotection. Proc Natl Acad Sci U S A 113, E1655-1662, doi:10.1073/pnas.1523680113 (2016).

62022 Jallet, D., Gwizdala, M. \& Kirilovsky, D. ApcD, ApcF and ApcE are not required for the Orange Carotenoid Protein related phycobilisome fluorescence quenching in the cyanobacterium Synechocystis PCC 6803. Biochim Biophys Acta 1817, 1418-1427, doi:10.1016/j.bbabio.2011.11.020 (2012).

23 Stadnichuk, I. N. et al. Site of non-photochemical quenching of the phycobilisome by orange carotenoid protein in the cyanobacterium Synechocystis sp. PCC 6803. Biochim Biophys Acta 1817, 1436-1445, doi:10.1016/j.bbabio.2012.03.023 (2012).

24 Kuzminov, F. I. et al. Investigation of OCP-triggered dissipation of excitation energy in PSI/PSII-less Synechocystis sp. PCC 6803 mutant using non-linear laser fluorimetry. Biochim Biophys Acta 1817, 1012-1021, doi:10.1016/j.bbabio.2012.03.022 (2012).

63025 Liu, H. et al. Structure of cyanobacterial phycobilisome core revealed by structural modeling and chemical cross-linking. Sci Adv 7, doi:10.1126/sciadv.aba5743 (2021).

26 Tian, L. et al. Site, rate, and mechanism of photoprotective quenching in cyanobacteria. $J \mathrm{Am}$ Chem Soc 133, 18304-18311, doi:10.1021/ja206414m (2011).

27 Rahmatpour, N. et al. A novel thylakoid-less isolate fills a billion-year gap in the evolution of Cyanobacteria. Curr Biol 31, 2857-2867 e2854, doi:10.1016/j.cub.2021.04.042 (2021).

28 Staleva, H. et al. Mechanism of photoprotection in the cyanobacterial ancestor of plant antenna proteins. Nat Chem Biol 11, 287-291, doi:10.1038/nchembio.1755 (2015).

29 Tian, L. et al. Picosecond kinetics of light harvesting and photoprotective quenching in wildtype and mutant phycobilisomes isolated from the cyanobacterium Synechocystis PCC 6803. Biophys J 102, 1692-1700, doi:10.1016/j.bpj.2012.03.008 (2012).

30 Kirst, H., Formighieri, C. \& Melis, A. Maximizing photosynthetic efficiency and culture productivity in cyanobacteria upon minimizing the phycobilisome light-harvesting antenna size. Biochim Biophys Acta 1837, 1653-1664, doi:10.1016/j.bbabio.2014.07.009 (2014).

31 Xie, Y. R., Chen, L., Sun, T. \& Zhang, W. W. Deciphering and engineering high-light tolerant cyanobacteria for efficient photosynthetic cell factories. Chinese J Chem Eng 30, 82-91, doi:10.1016/j.cjche.2020.11.002 (2021).

32 Kromdijk, J. et al. Improving photosynthesis and crop productivity by accelerating recovery from photoprotection. Science 354, 857-861, doi:10.1126/science.aai8878 (2016).

33 Araoz, R. \& Hader, D. P. Ultraviolet radiation induces both degradation and synthesis of phycobilisomes in Nostoc sp.: a spectroscopic and biochemical approach. Fems Microbiol Ecol 23, 301-313, doi:10.1111/j.1574-6941.1997.tb00411.x (1997).

34 Gantt, E., Lipschultz, C. A., Grabowski, J. \& Zimmerman, B. K. Phycobilisomes from bluegreen and red algae: isolation criteria and dissociation characteristics. Plant Physiol 63, 615620, doi:10.1104/pp.63.4.615 (1979).

Han, B. G. et al. Long shelf-life streptavidin support-films suitable for electron microscopy of biological macromolecules. J Struct Biol 195, 238-244, doi:10.1016/j.jsb.2016.06.009 (2016).

Tivol, W. F., Briegel, A. \& Jensen, G. J. An improved cryogen for plunge freezing. Microsc Microanal 14, 375-379, doi:10.1017/S1431927608080781 (2008). 
bioRxiv preprint doi: https://doi.org/10.1101/2021.11.15.468719; this version posted November $15,2021$. The copyright holder for this preprint (which was not certified by peer review) is the author/funder, who has granted bioRxiv a license to display the preprint in perpetuity. It is made available under aCC-BY-NC-ND 4.0 International license.

OCP-Phycobilisome Paper

37 Sun, M. et al. Practical considerations for using K3 cameras in CDS mode for high-resolution and high-throughput single particle cryo-EM. J Struct Biol 213, 107745, doi:10.1016/j.jsb.2021.107745 (2021).

38 Schorb, M., Haberbosch, I., Hagen, W. J. H., Schwab, Y. \& Mastronarde, D. N. Software tools for automated transmission electron microscopy. Nat Methods 16, 471-477, doi:10.1038/s41592-019-0396-9 (2019).

66539 Scheres, S. H. RELION: implementation of a Bayesian approach to cryo-EM structure determination. J Struct Biol 180, 519-530, doi:10.1016/j.jsb.2012.09.006 (2012).

40 Punjani, A., Rubinstein, J. L., Fleet, D. J. \& Brubaker, M. A. cryoSPARC: algorithms for rapid unsupervised cryo-EM structure determination. Nat Methods 14, 290-296, doi:10.1038/nmeth.4169 (2017).

41 Sanchez-Garcia, R. et al. DeepEMhancer: a deep learning solution for cryo-EM volume postprocessing. Commun Biol 4, 874, doi:10.1038/s42003-021-02399-1 (2021).

42 Emsley, P., Lohkamp, B., Scott, W. G. \& Cowtan, K. Features and development of Coot. Acta Crystallogr D Biol Crystallogr 66, 486-501, doi:10.1107/S0907444910007493 (2010).

43 Liebschner, D. et al. Macromolecular structure determination using X-rays, neutrons and electrons: recent developments in Phenix. Acta Crystallogr D Struct Biol 75, 861-877, doi:10.1107/S2059798319011471 (2019).

44 Wei, T. J., Balevicius, V., Polivka, T., Ruban, A. V. \& Duffy, C. D. P. How carotenoid distortions may determine optical properties: lessons from the Orange Carotenoid Protein. Phys Chem Chem Phys 21, 23187-23197, doi:10.1039/c9cp03574e (2019).

Kuznetsova, V. et al. Comparative ultrafast spectroscopy and structural analysis of OCP1 and OCP2 from Tolypothrix. Biochim Biophys Acta Bioenerg 1861, 148120, doi:10.1016/j.bbabio.2019.148120 (2020).

Zigmantas, D., Polivka, T., Hiller, R. G., Yartsev, A. \& Sundstrom, V. Spectroscopic and dynamic properties of the peridinin lowest singlet excited states. $J$ Phys Chem A 105, 1029610306, doi:DOI 10.1021/jp010022n (2001).

47 Polivka, T., Chabera, P. \& Kerfeld, C. A. Carotenoid-protein interaction alters the S(1) energy of hydroxyechinenone in the Orange Carotenoid Protein. Biochim Biophys Acta 1827, 248254, doi:10.1016/j.bbabio.2012.10.005 (2013).

Larkin, M. A. et al. Clustal W and clustal X version 2.0. Bioinformatics 23, 2947-2948, doi:10.1093/bioinformatics/btm404 (2007).

49 Kozlov, A. M., Darriba, D., Flouri, T., Morel, B. \& Stamatakis, A. RAxML-NG: a fast, scalable and user-friendly tool for maximum likelihood phylogenetic inference. Bioinformatics 35, 4453-4455, doi:10.1093/bioinformatics/btz305 (2019).

50 Capella-Gutierrez, S., Silla-Martinez, J. M. \& Gabaldon, T. trimAl: a tool for automated alignment trimming in large-scale phylogenetic analyses. Bioinformatics 25, 1972-1973, doi:10.1093/bioinformatics/btp348 (2009).

51 Crooks, G. E., Hon, G., Chandonia, J. M. \& Brenner, S. E. WebLogo: a sequence logo generator. Genome Res 14, 1188-1190, doi:10.1101/gr.849004 (2004).

52 Pettersen, E. F. et al. UCSF Chimera--a visualization system for exploratory research and analysis. J Comput Chem 25, 1605-1612, doi:10.1002/jcc.20084 (2004).

53 Goddard, T. D. et al. UCSF ChimeraX: Meeting modern challenges in visualization and analysis. Protein Sci 27, 14-25, doi:10.1002/pro.3235 (2018).

54 Krissinel, E. \& Henrick, K. Inference of macromolecular assemblies from crystalline state. Journal of Molecular Biology 372, 774-797, doi:10.1016/j.jmb.2007.05.022 (2007).

Laskowski, R. A., Watson, J. D. \& Thornton, J. M. ProFunc: a server for predicting protein function from 3D structure. Nucleic Acids Res 33, W89-93, doi:10.1093/nar/gki414 (2005).

56 Jurrus, E. et al. Improvements to the APBS biomolecular solvation software suite. Protein Sci 27, 112-128, doi:10.1002/pro.3280 (2018). 
bioRxiv preprint doi: https://doi.org/10.1101/2021.11.15.468719; this version posted November 15, 2021. The copyright holder for this preprint (which was not certified by peer review) is the author/funder, who has granted bioRxiv a license to display the preprint in perpetuity. It is made available under aCC-BY-NC-ND 4.0 International license.

OCP-Phycobilisome Paper 